DR OSVALDO DELBONO (Orcid ID : 0000-0002-1613-8202)

Article type : Regular Paper

\title{
The Sympathetic Nervous System Regulates Skeletal Muscle Motor Innervation and Acetylcholine Receptor Stability
}

Anna C. Zaia Rodrigues, ${ }^{1,6^{*}}$ Maria Laura Messi, ${ }^{1 *}$ Zhong-Min Wang, ${ }^{1 *}$ Martin C. Abba, ${ }^{7}$ Andrea Pereyra, ${ }^{1 \# \#}$ Alexander Birbrair, ${ }^{1 \#}$ Tan Zhang, ${ }^{1}$ Meaghan O'Meara, ${ }^{1}$ Ping Kwan, ${ }^{1,5}$

Elsa I. S. Lopez, ${ }^{2 \# \#}$ Monte S. Willis, ${ }^{8}$ Akiva Mintz, ${ }^{4 \# \# \#}$ D. Clark Files, ${ }^{3}$ Cristina Furdui, ${ }^{2}$ Ronald W. Oppenheim, ${ }^{5}$ and Osvaldo Delbono. ${ }^{1,6 \S}$

Department of Internal Medicine, Gerontology, ${ }^{1}$ Molecular Medicine, ${ }^{2}$ and Pulmonary, ${ }^{3}$ Department of Radiology, ${ }^{4}$ Department of Neurobiology and Anatomy, ${ }^{5}$ and Neuroscience Program, ${ }^{6}$ Wake Forest School of Medicine, Winston-Salem, NC 27157, USA. Basic and Applied Immunological Research Center (CINIBA), School of Medicine, National University of La Plata, Buenos Aires, Argentina, ${ }^{7}$ and McAllister Heart Institute and Department of Pathology, University of North Carolina-Chapel Hill. ${ }^{8}$

* These authors contributed equally to this work.

Current address: ${ }^{\text {\# }}$ Department of Pathology, Federal University of Minas Gerais, Belo Horizonte, Brazil. ${ }^{\text {D }}$ Department of Nutrition Science, College of Health and Human Sciences, Purdue University, West Lafayette, IN. ${ }^{\# \#}$ Department of Chemistry, Washington State University, Richland, WA. \#\#\#\# Division of Nuclear Medicine, Columbia University Medical Center, New York, NY.

\section{Abbreviated title: Sympathetic Nervous System and NMJ}

This article has been accepted for publication and undergone full peer review but has not been through the copyediting, typesetting, pagination and proofreading process, which may lead to differences between this version and the Version of Record. Please cite this article as doi: 10.1111/apha. 13195

This article is protected by copyright. All rights reserved. 
§Correspondence to: Osvaldo Delbono. Email: odelbono@wakehealth.edu

\begin{abstract}
Aim: Symptoms of autonomic failure are frequently the presentation of advanced age and neurodegenerative diseases that impair adaptation to common physiologic stressors. The aim of this work is to examine the interaction between the sympathetic and motor nervous system, the involvement of the sympathetic nervous system (SNS) in neuromuscular junction (NMJ) presynaptic motor function, the stability of postsynaptic molecular organization, and the skeletal muscle composition and function.
\end{abstract}

Methods: Since muscle weakness is a symptom of diseases characterized by autonomic dysfunction, we studied the impact of regional sympathetic ablation on muscle motor innervation by using transcriptome analysis, retrograde tracing of the sympathetic outflow to the skeletal muscle, confocal and electron microscopy, NMJ transmission by electrophysiological methods, protein analysis, and state of the art microsurgical techniques, in C57BL6, MuRF1KO and Thy-1 mice.

Results: We found that the SNS regulates motor nerve synaptic vesicle release, skeletal muscle transcriptome, muscle force generated by motor nerve activity, axonal neurofilament phosphorylation, myelin thickness, and myofiber subtype composition and CSA. The SNS also modulates levels of postsynaptic membrane acetylcholine receptor by regulating the $\mathrm{Ga}_{\mathrm{i} 2}-$ Hdac4-Myogenin-MuRF1pathway, which is prevented by overexpression of the guanine nucleotide-binding protein $\mathrm{G \alpha}_{\mathrm{i} 2}(\mathrm{Q} 205 \mathrm{~L})$, a constitutively active mutant $\mathrm{G}$ protein subunit.

Conclusion: The SNS regulates NMJ transmission, maintains optimal $\mathrm{G \alpha}_{\mathrm{i} 2}$ expression and prevents any increase in Hdac4, myogenin, MuRF1, and miR-206. SNS ablation leads to upregulation of MuRF1, muscle atrophy, and downregulation of postsynaptic AChR. Our

This article is protected by copyright. All rights reserved. 
findings are relevant to clinical conditions characterized by progressive decline of sympathetic innervation, such as neurodegenerative diseases and aging.

Key words: Skeletal muscle, muscle innervation, sympathetic nervous system, muscle denervation, neuromuscular junction.

\section{Introduction}

Autonomic nervous system failure is a manifestation of devastating acute and chronic diseases. Its functional impairment and resulting muscle weakness are conspicuous symptoms of Alzheimer's disease ${ }^{1}$ and such synucleinopathies as Parkinson's disease, dementia with Lewy bodies, multiple system atrophy, and pure autonomic failure. ${ }^{2-14}$ Muscle weakness associated with autonomic dysfunction is also obvious in adrenal insufficiency, Lambert-Eaton myasthenic syndrome, and chronic fatigue syndrome. ${ }^{15-17}$ Aging produces several changes in the autonomic nervous system that may impair adaptations to common physiologic stressors and increase the risk of developing diseases that further harm autonomic function.

The sympathetic nervous system (SNS), a branch of the autonomic nervous system, regulates the function of many tissues, and its genetic, autoimmune, or degenerative alteration results in a variety of clinical disorders affecting the brain, spinal cord, and/or nerve structure and function. It plays a role in skeletal muscle regeneration after injury ${ }^{18}$ and the ability to perform short intensive tasks like the Wingate test, ${ }^{19}$ and its deterioration with age results in incapacitating symptoms. ${ }^{20-22}$

This article is protected by copyright. All rights reserved. 
More than a century ago, dual innervation of the skeletal muscle, motor and sympathetic, was described. ${ }^{23-25}$ In 1970, Kuba reported that noradrenaline (NA), the main neurotransmitter of ganglionic sympathetic neurons, modulates neuromuscular transmission. ${ }^{26}$ Research on the association between progressive muscle atrophy and sympathetic paralysis of voluntary muscles identified "functional synapses" between preganglionic sympathetic axons and skeletal muscle. ${ }^{27-30}$ Sympathetic axons reach the muscle fiber ${ }^{31}$ via Remak fibers traveling through the peripheral nervous system ${ }^{32}$ and surrounding blood vessels. ${ }^{33,34}$ For a long time, sympathetic innervation of skeletal muscle was thought to be restricted to the blood vessels until it was observed in intra- and extrafusal fibers of the cat tenuissimus, soleus, extensor digitorum longus, peroneal, lumbrical, and diaphragm muscles. ${ }^{33}$ This finding generated interest in understanding the role of postganglionic sympathetic axons and their neurotransmitter(s) in myofiber composition and function.

For long time, skeletal muscle research was focused mainly in the relationship between catecholamines and membrane $\beta 2$-adrenoceptors (AR), ${ }^{35}$ probably due to the complexity of the SNS trajectory, neurotransmitters (noradrenaline, NA; ATP; and neuropeptide Y, NPY) and targets. Note that $\beta 1$ - and $\beta 2$-AR antagonists, such as propranolol, cause muscle weakness, ${ }^{36}$ while $\beta$-AR agonists enhance muscle strength in diseases characterized by congenital impaired neurotransmission. ${ }^{37} \beta_{2}$-AR expression predominates in skeletal muscle ${ }^{35}$ and mediates SNS action on the myofiber, and its agonists can remediate skeletal muscle sympathetic denervation, ${ }^{31}$ but chronic administration has serious side effects that preclude their therapeutic use for muscle-wasting conditions. ${ }^{38}$ Designing future interventions that can adjust neurotransmitter release to changes in physiological demands with physical activity and/or age depends on understanding the role of SNS in muscle motor innervation. In this study, we sought to clarify

This article is protected by copyright. All rights reserved. 
the role of the SNS in neuromuscular junction (NMJ) pre- and post-synapsis, motor axon and skeletal muscle innervation and function in sedentary mice.

The development of antibodies against key enzymes in the synthesis of NA, tyrosine hydroxylase $(\mathrm{TH})$ and dopamine- $\beta$-hydroxylase $(\mathrm{DBH})$ or transgenic $\mathrm{DBH}$ have been used to characterize postganglionic sympathetic axons' trajectory and connections to spinal cord and skeletal muscle. ${ }^{39-41}$ These techniques allowed for a direct assessment of the spatial relationship between the SNS and muscle innervation. A TH-positive immunoreaction at the NMJ was reported in monkey and human muscles, suggesting SNS innervation of the myofiber at the NMJ, ${ }^{42}$ while sympathetic neurons expressing the DBH-tomato transgene and immunoreactivity to a TH or NPY antibody showed coregistration at the mouse diaphragm muscle. ${ }^{31}$ In this study, by using TH immunoreactivity as well as transcriptome analysis, retrograde tracing of the sympathetic outflow to the skeletal muscle, confocal and electron microscopy, neuromuscular junction transmission by electrophysiological methods, protein analysis, and microsurgical or chemical sympathectomy in C57BL6, MuRF1KO and Thy-1 mice, we concluded that the SNS regulates NMJ pre- and post-synapsis, and muscle motor innervation and function.

\section{Results}

\section{Relationship between SNS and skeletal muscle innervation}

To examine the relationship between SNS and skeletal muscle innervation, we surgically removed the L2-L3 ganglia of the paravertebral chain, which supplies sympathetic innervation to hindlimb muscles (see Methods). Figure 1A shows the L2-L4 ganglia of the paravertebral chain after postmortem removing all abdominal organs. Due to bilateral connections and caudal fusion 
(Fig. 1A, bottom arrow), the sympathetic trunk was excised bilaterally. Lumbar ganglia sympathectomy was followed by confirmation of the neuronal type composition of the removed structure by immunostaining for TH+ neurons (Fig. 1B-D). Figure 1 shows two ganglia and their interspace devoid of sympathetic neurons $(\mathbf{B})$, and a ganglion with high sympathetic neurons density recorded with epifluorescence (C) and confocal (D) microscopy.

Previous studies established anatomical and histological relationships between the SNS and skeletal muscle but inferred their functional link from analysis of the interaction between NA and its receptor $(\beta 2-\mathrm{AR}) .{ }^{35}$ Although connectivity between muscle sympathetic terminals and neurons located in the spinal cord intermediolateral column has been reported, ${ }^{43}$ we sought to establish the relationship between the skeletal muscle and L2-L3 paravertebral sympathetic ganglia neurons, the SNS relay that we surgically removed in this study, by co-registering a retrogradely transported fluorescent agent with $\mathrm{TH}+$ neurons. We injected AlexaFluorconjugated cholera toxin subunit B (CTB) AF488 or AF555 in the TA or GA muscle, respectively, as our retrograde tracer. Figure 1E-J, shows ganglia neurons labeled with CTBAF488 (E) and CTB-AFAF555 (F) injected in the TA and GA muscles, respectively. Cell nuclei and soma were stained with Hoechst 33342 (G) and immunostained with TH antibody (H), respectively. Figures $1 \mathbf{I}$ and $\mathbf{J}$ show panels e-g and e-h overlaps, respectively. These results show a functional connection between mouse hindlimb muscles and paravertebral ganglia sympathetic neurons.

\section{The SNS regulates genes associated with skeletal muscle denervation}

Loss of connectivity between the spinal nerves and skeletal muscles leads to extensive transcriptome modifications; ${ }^{44}$ however, whether the SNS influences muscle gene transcription is unknown. To address this question we used the GA muscle for gene expression profiling by

This article is protected by copyright. All rights reserved. 
oligo-microarray because it is large and composed of several fiber types. ${ }^{45}$ The volcano plot and heatmap (Fig. 2A, B) show the 182 genes most significantly modified (fold change $>1.5$; $\mathrm{p}<$ 0.01) after surgical sympathectomy (see supplementary Excel file, worksheet sym_vs_sham), as confirmed by real-time PCR (qPCR) of randomly selected genes (Fig. S1). They can be grouped into several signaling pathways regulating muscle metabolism, circadian rhythm, gene transcription, and soluble $N$-ethylmaleimide-sensitive factor attachment protein receptor (SNARE)-interacting proteins (Figs. 2C, S2). The following gene transcripts decreased to varying extents (14-78\%): genes encoding synaptic vesicle docking and fusion (syntaxin binding protein-1 [Stxbp 1]); members of the Notch signaling pathway (neuralized E3 ubiquitin protein ligase $1[$ Neural1]); the circadian rhythm gene (periodic circadian clock $1[$ Perl]); proteins that interact with the SNARE, such as vesicle-associated membrane protein 3 (VAMP3), or vesicle transport through interaction with t-SNAREs homolog 1B (VTI1b); transcription factors (Forkhead box protein P1 [Foxp1]) or transcription factor binding proteins (CREB-binding protein $[C R E B B P])$; protein kinase $\mathrm{B}[\mathrm{PKB}$ or $A k t 1]$ ); and ubiquitin ligases (ubiquitinconjugating enzyme E2 G2 [UBE2G2]) (Fig. S1). In contrast, genes associated with muscle motor denervation, such as Chrng and myogenin (Fig. 11A), were upregulated in both GA and TA muscles (225\% and 68\%, respectively) on day 7 after sympathectomy. Other genes (Musk and $M y o D)$ showed only marginal changes (-1\% to 3\%) at the same timepoint (Fig. S1). Based on a report that after sciatic nerve axotomy, the soleus muscle upregulates $M y o D$ earlier and more strongly than the GA muscle does, ${ }^{46}$ we examined $M y o D$ transcript levels in the soleus muscle from sham and sympathetic denervated mice. Data included in Figure S1 for MyoD-Sol, show a 375\% upregulation. Since sympathectomy results in upregulation of genes reportedly increased with muscle motor denervation (Chrng, MyoD, and myogenin $)^{47,48}$ and

This article is protected by copyright. All rights reserved. 
downregulation of synaptic vesicle docking and fusion (Stxbpl) and presynaptic SNARE proteins (Vamp3 and VtI1b), we examined whether the SNS regulates motor axon synaptic vesicle release and postsynaptic AChR stability.

\section{The SNS regulates NMJ transmission and skeletal muscle force generated by motor nerve} stimulation

Upregulation of genes associated with muscle denervation suggests that SNS ablation leads to alterations in NMJ transmission and muscle force generation capacity. We conducted functional recordings in a plantar nerve-lumbricalis muscle preparation for the following reasons, few myofiber layers, banded alignment of the NMJs, and parallel arrangement of its tendons. ${ }^{49}$

Figure 3A illustrates these features in a plantar nerve-lumbricalis muscle preparation from a B6.Cg-Tg(Thy1-YFP)HJrs/J-line 16 mouse that marks motor and sensory but not sympathetic axons. ${ }^{50}$ Also, the SNS in this muscle shows profuse $\mathrm{TH}+$ terminal arborization, some of it in the proximity of labeled $\alpha$-bungarotoxin+ NMJ postterminals when the muscle is treated with iDISCO (Fig. 3B). However, despite overlap in the 2D projections (Fig. 3B), sympathetic axons did not show axonal terminals at the gutters of the postterminals when the NMJs were examined with a confocal microscope and in 3D reconstructed images (video 1). Thus, $\mathrm{TH}+$ axons run proximate to the $\alpha-\mathrm{BGT}+$ postterminals of the lumbricalis muscle. In contrast to the sympathetic innervated lumbricalis muscle illustrated in Figure 3B, the panel C shows that TH immunoreactivity completely disappeared 7 days after sympathetic denervation (n =8-10 muscles from 6 sympathectomized or sham-operated mice).

This article is protected by copyright. All rights reserved. 
Upregulation of genes associated with muscle denervation suggests that the amplitude of muscle force generated in response to motor nerve stimulation should be lower than that elicited by direct muscle stimulation. If NMJ transmission is impaired after SNS ablation, muscle force evoked by nerves, may lead to a lower and unsustained tetanic force. Figure $\mathbf{3}$ shows that sympathectomy causes a significant reduction in the indirect (nerve-evoked)/direct (muscleevoked) contraction force ratio in the $20-150 \mathrm{~Hz}$ stimulation range (D). Also, a progressive decline in nerve-evoked maximum force amplitude, or an unsustained plateau, was observed in sympathectomized (F) but not sham (E) mice. SNS ablation evokes significant loss in lumbricalis force and muscle mass. Seven days after sympathectomy, we measured significant decreases in absolute force (sham: $55 \pm 6.2 \mathrm{mN}$; sympathectomized: $46 \pm 7.1, \mathrm{n}=8$ muscles from 4 mice per group; two-tailed $P$ value $=0.017)$ and muscle fiber CSA (sham: $205 \pm 31 \mu \mathrm{m}^{2}$; sympathectomized: $164 \pm 22, \mathrm{n}=120$ fibers from 6 muscles and 4 mice per group; two-tailed $P$ value $=0.025$ ). Figure 3 also shows twitches recorded in the peroneal nerve-lumbricalis muscle preparations from sham $(\mathbf{G})$ and sympathectomized $(\mathbf{H})$ mice used for high- frequency stimulation. Consistent with the tetanic responses, twitches are smaller in the directly stimulated sympathectomized lumbricalis muscles, and their amplitude decreased further when indirectly stimulated.

To define why nerve-evoked muscle contraction is depressed compared to direct muscle stimulation, we performed electrophysiological recordings in the plantar nerve-lumbricalis muscle preparation from sympathectomized and sham-operated mice described above to determine whether the SNS regulates neuromuscular transmission. Spontaneous miniature endplate potentials (MEPPs) were continuously recorded for 5 minutes in myofibers exhibiting a resting membrane potential (RMP) of $-60 \mathrm{mV}$ or more negative. Sarcolemmal RMP was slightly 
depolarized by sympathectomy (sham, $-62 \pm 1.2 \mathrm{mV}, \mathrm{n}=49$; sympathectomy, $-59 \pm 1.2 \mathrm{mV}, \mathrm{n}=$ 54), but differences were not statistically significant $(p=0.067)$. Figure 3I shows selected MEPP recordings from sympathectomized and sham mice. Table 1 shows a significant decrease in amplitude, frequency, half-decay time, and duration in sympathectomized compared to sham mice as an indication of impaired pre- and postsynaptic function.

Next, we analyzed end-plate potential (EPP) amplitude at increasing stimulation frequencies (2-150Hz for 1s) in sympathectomized and sham mice (Fig. 3J). Each electrical pulse was followed by an EPP in all experiments. Note the $\sim 28 \%$ reduction in EPP amplitude in fibers from sympathectomized compared to sham mice. Table 1 shows that sympathectomy significantly decreased EPP amplitude and quantal content, while EPP kinetics did not differ between groups. NMJ plasticity, measured by recording EPP facilitation and depression, did not differ significantly between sympathectomized and sham mice at this timepoint (Table 2). These results indicate that the SNS regulates NMJ transmission and skeletal muscle force elicited by motor nerve stimulation.

\section{SNS ablation induces smaller axon cross-sectional area, extensive axonal neurofilament} disorganization and dephosphorylation and decrease in postsynaptic area

Marked presynaptic modifications in NMJ transmission, characterized by reduced MEPP frequency and EPP quantal content following sympathectomy, and impaired muscle tetanic contraction evoked by repetitive motor nerve stimulation prompted us to examine neurofilament (NF) phosphorylation and synaptic vesicle density and area at the motor axon terminals.

This article is protected by copyright. All rights reserved. 
Since phosphorylation regulates the NF network, its interactions with microtubules, ${ }^{51,52}$ synaptic vesicles' axonal transport toward the preterminal, ${ }^{53,54}$ and synaptic plasticity, ${ }^{55}$ we reasoned that by increasing the affinity of NF to microtubules, ${ }^{51} \mathrm{NF}$ dephosphorylation might influence synaptic vesicles transport. ${ }^{56}$ More recently, others reported that NF subunits are integral components of synapses and modulate neurotransmission, ${ }^{57}$ which could explain the preterminal functional alterations reported in Figure 3 and Table 1. NMJ innervation was examined in sham (Fig. 4A, C, E, and G) and sympathectomized (Fig. 4B, D, F, and H) thy-1 transgenic mice. Thy-1+ motor axon terminals (A, B) co-register with nonphosphorylated NF $(\mathbf{C}$, D). Similarly, Thy-1+ axons (E) overlap with phosphorylated NF in sham (G) but not sympathectomized mice $(\mathbf{F}, \mathbf{H})$. These data indicate that SNS ablation leads to extensive NF dephosphorylation.

To examine the reserve of synaptic vesicles (SVs), we focused our confocal microscopic analysis on the trajectory of motor axons immunostained with SV2 antibody in Thy-1 transgenic mice in sham (Fig. 4I, K) and sympathectomized (Fig. 4J, L) mice. Panels $\mathbf{I}$ and $\mathbf{J}$ show Thy-1+ motor axons in green and $\alpha-B G T+$ postterminals in blue. SV2 immunostaining outlines the axonal terminals in sham $(\mathbf{K})$ but less pronounced in sympathectomized (L) mice. SV2 staining of vesicles, most likely corresponding to sympathetic axons surrounding blood vessels (I, K, yellow arrows) and motor terminals (white arrows), are reduced by sympathectomy (L); however, SV2 clearly outlines the axonal terminal in both sham and sympathectomized mice. These data indicate that SNS ablation does not deplete large axons terminals from synaptic vesicles.

To quantify myofiber innervation, we measured the fractional occupancy of postsynaptic endplates using SV2 or synaptophysin immunoreactivity overlapping the postterminal BGT+ area. The postsynaptic area in sham-operated $\left(255 \pm 31 \mu \mathrm{m}^{2}\right)$ and sympathectomized $(187 \pm$ 
$\left.28 \mu \mathrm{m}^{2}\right)$ mice decreased significantly $(P<0.001)$. Our results show a decrease in area as reported for the chemically sympathectomized mice. ${ }^{58}$ Presynaptic terminal immunoreactivity to SV2 shows an almost complete occupancy of the postterminal in sham (96 $\pm 2.2 \%$; 77 NMJs) (Fig. 4M and $\mathbf{O})$ and sympathectomized $(94 \pm 3.4 \%, 68 \mathrm{NMJs})(\mathbf{N}, \mathbf{P})$ lumbricalis mice $(\mathrm{p}=0.358)$. Since synaptophysin is a synaptic vesicle protein phosphorylated by the nonreceptor tyrosine kinase src, ${ }^{59,60}$ we also examined the synaptophysin fractional occupancy of postsynaptic endplates. Synaptophysin immunoreactivity significantly decreased in sympathectomized (47 \pm $3.2 \%, 85 \mathrm{NMJs})$ compared to sham-operated $(85 \pm 2.9 \%, 92 \mathrm{NMJs})$ mice $(\mathrm{p}<0.01)$. NMJs were assessed on 4-5 lumbricalis muscles from 3 mice per group. Figure 4 also shows the close-up of a terminal immunoreactive to synaptophysin (s) that fully overlaps with the postterminal $(\mathbf{Q})$ in a sham mouse, while the postterminal in $(\mathbf{R})$ did not $(\mathbf{T})$ in a sympathectomized mouse. Whether sympathectomy evokes dephosphorylation, rendering synaptophysin less reactive to the antibody, is unknown but offers a potential explanation. The antibody clone YE269 is raised against human aa250-350 of the C-terminus, which encompasses 3 phosphorylation sites, and the tyrosine phosphatase SH-PTP1 immunoprecipitates in a complex with synaptophysin and src. ${ }^{61}$

Figure 5 show levels of NF-H (A), NF-M (B), NF-L (C), phosphorylated NF-H and NF$\mathrm{M}(\mathbf{D})$, protein phosphatase $2(\mathrm{PP} 2 \mathrm{~A})(\mathbf{E})$, and protein phosphatase $1(\mathrm{PP} 1)$ phosphatases $(\mathbf{F})$ in the lysates of both sciatic-tibio-peroneal nerves from 3 sham and 3 surgically sympathectomized mice. Blots and SDS PAGE were probed for GAPDH and Coomassie blue $(\mathbf{G}, \mathbf{H})$, respectively. Quantification of the NF immunoblots normalized to GAPDH show a significant increase in NFH and NF-M but not NF-H-L (i) with sympathectomy. Analysis of the phosphorylated (NFP)/nonphosphorylated (NF) ratio (J) showed decreased phosphorylation of both NF-H and NF-M subunits with sympathectomy. To examine whether the decreased NF-H and NF-M

This article is protected by copyright. All rights reserved. 
phosphorylation is associated with protein dephosphorylation, we measured levels of PP2A (E) and PP1 (F) phosphatases and found that both are significantly increased with sympathectomy $(\mathbf{K})$ as represented in their individual measurements normalized to GAPDH (L).

Electron micrographs showed NF and microtubule dissociation in tibioperoneal nerves from sham (Fig. S4A, C) but not sympathectomized (B, D) mice, indicating that NF dephosphorylation induces its interactions with microtubules. ${ }^{52}$ Since our analysis was done 7 days after sympathectomy, and the NF half-life has been reported as 22 days, ${ }^{62}$ we did not expect any significant decrease in the number of NFs per area, actually we have recorded an increase in NF-H and NF-M by immunoblot (Fig. 5I). Density did not differ significantly between the tibioperoneal nerve of sympathectomized $\left(279 \pm 51 \mathrm{NF} / \mu \mathrm{m}^{2} ; \mathrm{n}=7\right.$ axons, 3 nerves from 3 mice $)$ and sham ( $296 \pm 43 ; \mathrm{n}=8$ axons, 3 nerves from 3 mice) mice. These results in sham mice are consistent with those reported in the distal sciatic nerve of young rats. ${ }^{63}$ Inclusion of the whole sciatic-tibio-peroneal nerve for immunoblot analysis but focused electron microscopy sections on the proximal tibio-peroneal nerve could explain apparent discrepancies between the increased NF-H and NF-M levels but conserved NF density. Due to the NF disorganization depicted in Figure S4B, D as opposed to S4A, C; we measured the distance between NFs in transmission electron micrographs of nerve transversal sections using the Nearest Neighbor Distances Calculation $^{64,65}$ plugin for Image-J software. The analysis includes 306 and 389 distances measured in 7 axons from 3 nerves in sympathectomized and 8 axons from 3 nerves in sham mice. Figure S4E shows that maximum counts for both groups are at the $72 \mathrm{~nm}$ center, followed by 54 and $89 \mathrm{~nm}$; however, a wider range of NF distances was observed in the sympathectomized mice. These results indicate that sympathectomy induces NF disorganization, characterized by increased dispersion in inter-NF distances.

This article is protected by copyright. All rights reserved. 
To further analyze the effect of sympathectomy on myelinated axons, we used toluidine-blue staining to examine myelin thickness and axonal diameter (Fig. 6A, B) and transmission electron microscopy (TEM) to examine mean SV area. A wider range of myelin thicknesses $(\mathbf{C})$ and a shift toward smaller axonal diameters (D) are prominent in distal tibial nerves in sympathectomized compared to sham mice, while no significant differences in mean SV area were recorded at the axonal boutons (E-G), consistently with immunofluorescence results in Fig. 4I-L. It will be of interest to examine in subsequent experiments SV depletion at later timepoints after sympathectomy.

How sympathetic denervation leads to changes in axonal diameter, myelin thickness, and SV depletion in the axon trajectory is uncertain. Sympathectomy activates expression of the neurotrophins brain-derived neurotrophic factor (BDNF), nerve growth factor (NGF), and glialderived nerve factor (GDNF) and neurotrophin receptor $\mathrm{p} 75\left(\mathrm{p} 75^{\mathrm{NTR}}\right)$ mRNAs in a range from $32-350 \%$ but does not modify the Schwann cell myelination program based on the analysis of cJun (AP1B1), EGR2 (Krox20), MBP, and MPZ (P0) transcripts in the sciatic-tibial nerve at day 7 after sympathectomy (Fig. 6H).

These results indicate that SNS ablation results in axon shift toward smaller CSA, thinner myelin sheet, NF and microtubule association as evidence of structural involvement of large myelinated axons in sympathectomized mice. Strong downregulation of ILK further support a cross-talk between the sympathetic and motor muscle innervation in physiological conditions; however, whether preterminal structural disarray accounts for the decreased synaptic vesicle release frequency and quantal content after sympathectomy reported above, is unclear at the present.

This article is protected by copyright. All rights reserved. 


\section{Sympathectomy induces selective myofiber atrophy and a shift in fiber subtype}

Since skeletal muscle sympathectomy compromises neuromuscular transmission, we reasoned that a natural consequence would be myofiber atrophy. Figure 7A shows representative hematoxylin- and eosin-stained TA and GA muscle cross-sections from sham (top panels) and sympathectomized (bottom) mice. The statistically significant myofiber atrophy observed in both muscles after sympathectomy (A) is quantified in (B). The histogram of frequency shows a decrease in fiber CSA for both muscles after sympathectomy (C).

To determine whether sympathectomy affected specific myofiber subtypes, we immunostained muscle cross-sections with antibodies specific for myosin-heavy chain isoforms and examined fiber type composition and CSA in the TA and GA muscles. Also, we determined whether sympathectomy differentially modifies myofiber composition and CSA in different muscles with a similar percentage of type-I fibers, such as GA and soleus muscles, as reported for peripheral nerve injury. ${ }^{46}$ Figure 7D shows representative TA and GA muscle cross-sections from sham (top panels) and sympathectomized (bottom) mice. Like GA, the soleus muscle showed an increased percentage of type I and a decrease in type IIa, but, here, the differences were statistically significant. The percentages of types IIb and IIx did not change with sympathectomy in either GA or soleus muscles (Fig. 7E). Moreover, in the GA, type-I fibers atrophied, and type-IIa CSA increased, but all soleus fibers exhibited a decrease in CSA with sympathectomy, which was statistically significant only for type-IIb and -IIx fibers (Fig. 7F). It

should be noticed that type-IIb fibers in soleus muscle have been reported previously. ${ }^{45,66}$ The decrease in myofiber CSA evoked by sympathectomy in the TA, GA, and soleus muscles is consistent with the reported dramatic decline in muscle NA after sympathectomy ${ }^{67}$ and the prevention of muscle wasting associated with aging and disease by administering $\beta 2$-AR

This article is protected by copyright. All rights reserved. 
agonists. ${ }^{35}$ Percent-loss in CSA was consistent with weight changes in 8 TA $(-21 \pm 1.6 \%)$, GA ($17 \pm 2.2 \%)$, and soleus $(-24 \pm 1.9 \%)$ muscles from 4 sympathectomized or 4 sham-operated mice.

The number of myofibers counted at the largest CSA did not change significantly with sympathectomy (TA sham: $3580 \pm 260$; TA sympathectomized: $3620 \pm 320, \mathrm{p}=0.87$; GA sham: $9650 \pm 520$, GA sympathectomy: $10020 \pm 780, \mathrm{p}=0.47 ; \mathrm{n}=4-5$ muscles per group and treatment). These data support a selective rather than a general decrease in muscle fiber size, which is consistent with a short-term neurogenic atrophy.

\section{Sympathectomy decreases membrane AChR but not Chrnal transcription}

Since our electrophysiological data support the idea that sympathectomy triggers NMJ postsynaptic modifications, we performed AChR pull-down and immunoblot analyses to determine sarcolemmal (Fig. 8A, B) and total $\mathrm{AChR}(\mathrm{C}, \mathbf{D})$ protein levels. Figure 8A, B shows that $\mathrm{AChR}$ decreased in GA and TA muscles from sympathectomized compared to sham mice. Since MuRF1 is located near the postterminal synapse and plays a role in AChR turnover, ${ }^{68}$ we examined whether MuRF1KO precludes the effect of SNS ablation on membrane AChR; in a mouse model of constitutive TRIM 63 ablation, KO prevented the decline in postterminal membrane AChR expression. As expected, GA and TA muscles from sham MuRF1KO exhibited higher levels of membrane AChR than sham wild-type mice, which is explained by MuRF1 role in AChR recycling. ${ }^{68}$ To determine whether the decrease in AChR protein at day 3-7 after sympathectomy is regulated transcriptionally, we measured Chrnal mRNA at day 7 (Fig. 11A) and day 3 after sympathectomy (Fig. 11B). A minor increase in gene expression was observed

This article is protected by copyright. All rights reserved. 
from day 3 to 7 in the GA but not the TA, indicating that membrane' AChR downregulation occurs at the protein, not the transcript, level.

In contrast, the total pool of muscle AChR increased in the GA but was not modified in the TA following SNS ablation and was enhanced by MuRF1KO in both sympathectomized and sham mice (Fig. 8C, D). These results support the idea that SNS favors AChR redistribution and membrane insertion at the NMJ postterminal.

\section{Sympathectomy induces an increase in muscle MuRF1 by decreasing Goi2 and activating the}

\section{Hdac4- myogenin-MuRF1pathway}

To examine the mechanism by which sympathectomy decreases membrane AChR, we measured the E3-ligase MuRF1 in GA and TA muscles from sympathectomized mice, it increased significantly (Fig. 9A). At day 3 but not day 7 after sympathectomy, MuRF1 mRNA was significantly higher than in sham mice (GA: 102\%; TA: 97\%) (Fig. 11A, B). Desynchronized elevation of transcript and protein has been reported for this and other genes with sciatic denervation and spinal cord injury, ${ }^{69}$ indicating early and transient gene overexpression after surgery. Increased MuRF1 protein and mRNA do not seem to depend on significant changes in IкB, Akt, or NFkB (Fig. 9 B-D) phosphorylation following sympathectomy.

We also found that histone deacetylase-4 (Hdac4) increased in the GA (Fig. 10A), and myogenin increased in both muscles (Fig. 10B). Transcript levels for Hdac4 were higher at day 3 (GA: 153\%; TA: 210\%) than day 7 (GA: 79\%; TA: 91\%), while Fbxo32 (aka MAFbx or atrogin1) was higher at day 7 (TA: 245; GA: 215\%) than day 3 (TA: 141; GA: 96\%). Transcripts for FoxO1, FoxO3 did not vary appreciably between timepoints (Fig. 11A, B). Myogenin protein was significantly increased at day 7 (Fig. 10B), corresponding to increases in gene expression at

This article is protected by copyright. All rights reserved. 
day 7 (GA: $161 \%$; TA: $173 \%$ ). Levels of $\beta 2$-AR showed a small but significant increase in the TA but not the GA (Fig. 10C). Since myogenin regulates miRNA-206 and, through it, muscle reinnervation, ${ }^{70}$ we measured miRNA-206 levels and found elevated levels (220\% and $\left.73 \%\right)$ in TA and serum, respectively, but not in GA muscle, at day 7 after sympathectomy (Fig. 11C).

The SNS signals through cAMP/protein kinase-A (PKA) to regulate MuRF1 levels. ${ }^{67}$ After sympathectomy, PKA (RI $\alpha)$ increased, while PKA (RII $\alpha)$ did not change, so the PKA (RIIa)/ PKA (RIa) ratio decreased (Fig. S5), possibly contributing to the impaired neuromuscular transmission associated with increased cardiac troponin-T in the NMJ postterminal, as previously proposed. ${ }^{71}$

\section{Like surgery, chemical sympathectomy regulates skeletal muscle innervation}

We wanted to determine whether sympathectomy induced by a method other than surgery also regulates skeletal muscle innervation, so we administered $6(\mathrm{OH}) \mathrm{DA}$ for either one or two weeks. Figure S6 shows Hdac4, myogenin, MuRF1, Chrng, Chrnal, and Gadd45a muscle mRNA levels at days 7 and 14 afterward. Myogenin and Chrng in the GA, but only the first in the TA were significantly upregulated 14 days after treatment, while the six transcripts were not significantly different 7 days after chemical sympathectomy. Immunoblot analysis confirmed that 2 weeks of this treatment increased $\beta 2-A R$ and Hdac 4 in the GA and decreased $\mathrm{G}_{\alpha \mathrm{i} 2}$ in both GA and TA muscles (Fig. S7). Changes are less obvious at one week, which indicates that $6(\mathrm{OH}) \mathrm{DA}$ requires more time than surgical sympathectomy to induce muscle motor denervation. Percent-loss in muscle CSA after chemical sympathectomy is consistent with weight changes after surgical sympathectomy in TA (day 7: $-16 \pm 1.4 \%$; day $14:-22 \pm 1.9 \%)$, GA (-15 $\pm 2.3 \%$; $19 \pm 2.6 \%)$, and soleus $(-16 \pm 2.0 \% ;-25 \pm 3.1 \%)$ muscles. These data indicate that after chemical 
sympathetic ablation, muscle mass changes similar to those found in surgically treated mice take longer to develop. These results show that sympathectomy results in skeletal muscle motor innervation dysregulation, regardless of the procedure used to induce it.

\section{Constitutive active G $\alpha_{i 2}($ Q205L) expression precludes Hdac4-Myogenin-MuRF1 pathway activation in the TA muscle}

A previous study reported a significant decrease in NA $(>80 \%)$ in soleus and EDL muscles after sympathectomy using the same surgical technique, while plasma catecholamines did not differ between sympathectomized and sham mice. ${ }^{67}$ Since the $\beta 2$-AR is a heterotrimeric guanine nucleotide-binding protein ( $\mathrm{G}$ protein)-coupled receptor, and muscle noradrenaline NA levels and receptor activity decrease with sympathectomy,${ }^{67}$ we examined whether sympathectomy led to decreased $\mathrm{G \alpha}_{\mathrm{i} 2}$ activation, a mechanism postulated to activate myogenin. ${ }^{72} \mathrm{We}$ found that $\mathrm{G} \alpha_{\mathrm{i} 2}$ (Fig. 10D) significantly decreased in the GA and TA muscles after sympathectomy.

The human $\mathrm{G \alpha}_{\mathrm{i} 2}(\mathrm{Q} 205 \mathrm{~L})$ mutant, subcloned into an $\mathrm{AAV}$ vector was injected 3 and 4 weeks before mouse sympathectomy and euthanasia, respectively. Although both muscles show statistically significant difference in $\mathrm{G \alpha}_{\mathrm{i} 2}$ expression between surgically sympathectomized and sham mice, only the TA muscle was injected because it is smaller than the GA, showed more significant atrophy with sympathectomy (Fig. 7B), and requires significant less amount of virus. AVV- Ga $\alpha_{i 2}(\mathrm{Q} 205 \mathrm{~L})$ expression prevented decreases in membrane AChR levels (Fig. 8A, B), and increases in MuRF1 (Fig. 9A), Hdac4 (Fig. 10A), Myogenin (Fig. 10B) and $\beta 2-A R$ (Fig. 10C) expression induced by sympathectomy. These results indicate that increased muscle levels of $\mathrm{Ga}_{\mathrm{i} 2}$ prevent evidence of sympathectomy-induced skeletal muscle motor denervation (Fig. 12).

This article is protected by copyright. All rights reserved. 


\section{Discussion}

The NMJ is a specialized synapse, anatomically modeled as a tripartite structure consisting of an alpha motor neuron terminal, a myofiber postterminal, and perisynaptic Schwann cells. ${ }^{73}$ The NMJ plays a critical role in sustaining muscle mass, strength, posture, and locomotion throughout life. ${ }^{21}$ Defining the mechanisms by which the SNS regulates these neuromuscular properties may also have broad health implications, particularly on gait and mobility in older adults. That the SNS regulates neuromuscular junction function and maintenance was recently reported. ${ }^{31}$ Due to the widespread distribution of the SNS and the established link with physical disability, investigating the impact of its focal ablation on neuromuscular junction transmission is needed. To achieve this goal, we performed a state-of-art microsurgical procedure to selectively remove sympathetic innervation of mouse hindlimb muscles without interfering with central sympathetic nuclei function, cardiac sympathetic innervation, the sympathoadrenomedullary system, or motor axons innervating the skeletal muscle. In contrast to the classical model of muscle denervation, in which sectioning the sciatic nerve or any of its branches engages sympathetic, sensory, and motor axons, and unlike prolonged chemical procedures, such as systemic $6(\mathrm{OH}) \mathrm{DA}$ administration, which induce sympathetic denervation, 74-77 our procedure selectively depletes hindlimbs supplied exclusively by L2-L3 paravertebral sympathetic ganglia. ${ }^{78}$

This study demonstrates that ganglionic sympathetic neurons establish a bi-directional functional connection with the skeletal muscle and extensively regulate the skeletal muscle transcriptome, motor synaptic vesicle release, large axon diameter and myelin thickness, probably through NF phosphorylation, and postsynaptic AChR stability and muscle fiber innervation through regulating $\mathrm{G \alpha}_{\mathrm{i} 2}$, Hdac4, myogenin, MuRF1 and miR-206 levels. Treatments 
for conditions characterized by loss of muscle mass and force, such as aging may benefit by targeting the SNS in addition to skeletal muscle.

\section{The SNS extensively regulates the skeletal muscle transcriptome}

SNS ablation leads to up- and down-regulation of the skeletal muscle genes involved both in proteolytic ${ }^{78}$ and non-proteolytic events, including synaptic vesicle docking and fusion, circadian rhythm, gene transcription, the Notch pathway, and those engaging SNARE interacting proteins, $A k t 1$, and ubiquitin ligases. Although many of these genes are downregulated, those associated with muscle motor innervation, such as Chrng and myogenin, were upregulated in both GA and TA muscles. Our data included in Figs. 2, 11, S1 and S2 show that gene expression changes with time after sympathectomy. The transient elevation of Murfl at day 3 shown in Figure 11 is followed by a more sustained expression of myogenin and Chrng between days 3 and 7 after sympathectomy. Whether the transcriptome profile changes beyond day 7 after surgery is unknown. We do not expect that one week of muscle sympathetic denervation fully recapitulates the muscle transcriptome changes reported for a complete spinal nerve axotomy. However, our data do show the activation of a motor denervation program similar to that described for experimental motor denervation and Amyotrophic Lateral Sclerosis. ${ }^{70,79}$ Whether MyoD is modified at different timepoints than those used in our study is unknown. Based on a report that after sciatic nerve axotomy, the soleus muscle upregulates $M y o D$ earlier and more strongly than the GA muscle does, ${ }^{46}$ we examined $M y o D$ transcript levels in the soleus muscle from sham and sympathetic denervated mice. $M y o D$ in the soleus muscle shows a $375 \%$ upregulation, which further supports the concept that hindlimb muscle surgical sympathectomy promotes increased transcription of genes reported to be elevated during muscle motor

This article is protected by copyright. All rights reserved. 
denervation. However, the gene transcription activated by sympathectomy seems to be desynchronized across the hindlimb muscles. Based on this finding, we decided to explore the mechanisms by which SNS ablation leads to dysregulation of skeletal muscle innervation and, ultimately, their functional impact.

Differences in the arrays and the number of unique IDs for each platform make direct comparison of our dataset with that published on mouse sciatic muscle denervation ${ }^{44}$ difficult. We used an MG-430 Gene Atlas array strip, while they used a Muscle Array 1.0; the printed DNA probes used to hybridize with the experimental cDNAs on the slides differ. Our array provided 21,679 unique IDs and theirs $\sim 900$ at day 7 post-denervation. Despite this big difference in comparable genes, a substantial number are down- (202) or up- (279) regulated in both datasets. Almost half of the genes with unique IDs in their microarray (481) are similarly regulated by sympathetic denervation. The Supplementary Excel file twoDataSets_comparison GSE1893 and WF, provides a detailed analysis. Using DAVID functional assessment, we found that the 202 downregulated and 279 upregulated genes in the two datasets clustered into 60 gene ontology (GO) term enrichment and KEGG pathways. As expected for interventions that induce widespread cell modifications, these clusters include a large set of genes that regulate myofiber molecular composition and function (see also Fig. 2 and $\mathbf{S 2}$ in this manuscript and Fig. 3 and Table 2 in ${ }^{44}$ ).

Still, transcriptome differences between sympathetic and motor denervation exist. Since we surgically interrupted only sympathetic, not motor, muscle axons, we expected out-of-phase changes in gene transcription between the two interventions. Also, the amplitude of changes in gene expression after denervation varies significantly in the literature. Our microarray database and quantitative qPCR consistently show no significant elevations in Gadd45a mRNA in the first 
week after sympathectomy. Although Bongers et al. reported a large increase using qPCR, ${ }^{80}$ Raffaello et al. reported a more modest increase using a microarray and $\mathrm{qPCR} .{ }^{44}$ Based on these methods, Gadd45a mRNA levels oscillate in the first two weeks after denervation, tending to decrease between days 3 and 7. Although Cohen et al. reported a 15-fold increase in Hdac4 at day 7 after muscle denervation, ${ }^{81}$ Furlow et al. reported a 3-fold increase at day 3, consistent with our data. ${ }^{82}$ The time course of Hdac4 mRNA upregulation also varies in the literature, peaking at day 2 then declining ${ }^{80}$ or at day 7 with no later information provided. ${ }^{81}$

Differences in gene expression can be explained by various factors: (a) The length of the nerve stump: surgical sympathetic denervation takes place at the lumbar paravertebral sympathetic ganglia chain, while motor denervation by axotomy of the sciatic nerve takes place at the trochanter level, closer to the hindlimb muscles, and evokes earlier signs of muscle denervation. (b) Variation in the transcript probes between arrays, as mentioned above. (c) Differences in the muscles examined. We looked at GA, and Raffaello et al., ${ }^{44}$ TA. (d) Direct motor axotomy leads to irreversible muscle denervation, while sympathectomy can evoke a process of motor denervation and reinnervation, which would account for the qualitative and quantitative differences between the interventions. (e) Although NMJ proximity to sympathetic ramifications appears to be a general feature, the precise morphological interaction may vary between muscle types ${ }^{83}$ which would account for the differences in the initiation and development of dysregulated muscle motor innervation that sympathetic ablation evokes.

Despite these caveats, global similarities exist, prompting us to propose that the SNS regulates skeletal muscle innervation.

This article is protected by copyright. All rights reserved. 
In addition to this analysis, a series of findings support SNS regulation of muscle innervation, including: (a) genes associated with muscle motor denervation, such as Chrng, MyoD, Fbxo32, and myogenin; synaptic vesicle docking and fusion (Stxbp1); and presynaptic SNARE proteins (Vamp3 and VtIlb); (b) NMJ transmission and skeletal muscle force generated by motor nerve stimulation; (c) selective fiber atrophy in three hindlimb muscles (TA, GA, and soleus); (d) axon cross-sectional area, axonal neurofilament organization and phosphorylation, and postsynaptic area; (e) AChR levels; and (f) activation of the Hdac4-myogenin-MuRF1-miR-206 pathway, which is also activated by motor denervation, among other major changes.

Muscle and circulating levels of miR-206 play an important role in muscle innervation and myofiber nuclear signaling triggered by denervation. ${ }^{70,79}$ Here, we report increased miR-206 in TA but not GA muscles and elevation in serum a week after lumbar sympathetic denervation. That miR-206 is elevated in the TA but not the GA strengthens this finding's significance. Levels of miR-206 depend on the relative proportion of fast- and slow-fiber composition; elevation is associated with muscles predominantly composed of fast-type fibers; decrease, with slow-type fibers; and no change with mixed fiber-type composition. ${ }^{84,85}$ Since myomiRs are expressed in both cardiac and skeletal muscle, but miR-206 is skeletal muscle-specific, ${ }^{86}$ so its serum levels reflect the balance between myofiber expression and the magnitude of extrusion to circulation. Elevated serum levels of miR-206 in response to sympathetic denervation indicate that fast fibers are contributing more than slow fibers to circulating levels.

\section{The SNS regulates NMJ transmission and muscle force generation}

Previous work has shown that administration of sympathomimetic agents prevents the effects of chemical sympathectomy, demonstrating that SNS innervation controls homeostasis of NMJs; ${ }^{31}$ however, the mechanism is unknown. We found a significant decrease in (a) MEPP amplitude,

This article is protected by copyright. All rights reserved. 
frequency, half-decay time, and duration and (b) EPP amplitude and quantal content in sympathectomized compared to sham mice. Decreased EPP amplitude reflects less evoked ACh release,${ }^{87}$ while reduced quantal content reflects fewer ACh transmitters in the synaptic vesicles, ${ }^{88}$ indicating that SNS ablation induces both presynaptic and postsynaptic alterations. Alterations in NMJ transmission lead to decreased muscle force generation in response to short (twitch) and prolonged (tetanus) motor nerve stimulation.

\section{SNS ablation leads to increased spinal nerve expression of genes encoding neurotrophins and extensive motor axon neurofilament dephosphorylation}

A decrease in synaptic vesicle release and quantum content indicates that motor axon function is impaired, but how sympathetic and motor axons in the spinal nerve communicate under normal and pathological conditions is unknown. To examine this, we examined whether sympathectomy alters myelination, myelin thickness, and/or NF phosphorylation in large axons like those in motor neurons. We found an increased variability in myelin thickness, which might be associated with activation of Schwann cell reprogramming. ${ }^{89}$ Myelinating Schwann cells modulate NF phosphorylation, axonal caliber, and slow axonal transport. ${ }^{90}$ Although our analysis at the sciatic-tibio-peroneal nerve showed no downregulation of genes encoding axonal myelination, we found a reactive increase in neurotrophin gene transcription. NFs are abundant in motor and other neurons with large axonal diameters. ${ }^{91,92}$ The mechanism underlying cross-talk between sympathetic and motor axons remains unclear. The dephosphorylated NF interaction with microtubules revealed by TEM may interfere with the transport of enzymes and peptide precursors via microtubules. ${ }^{93}$

This article is protected by copyright. All rights reserved. 
The phosphorylation state of NF proteins is the result of a dynamic balance between the levels and activity of kinases and phosphatases. ${ }^{55}$ By comparing the phosphorylation status of peroneal nerve innervating the lumbricalis muscle by immunofluorescence and the immunoblot analysis, we realize that the magnitude of nerve dephosphorylation is much larger in the former; however, it must be noted that immunofluorescence was recorded in the most distal segment of the peroneal nerve, while immunoblots required a lysate of the whole sciatic-tibial-peroneal nerve. A distal-to-proximal NF dephosphorylation gradient could explain the higher impact of nerve dephosphorylation on the nerve innervating the lumbricalis than the whole extension of the sciatic-tibial-peroneal nerve, which is consistent with the reported substantially more phosphatase activity in nerve terminals. ${ }^{94}$ This proposal is further supported by our data showing an extensive but partial loss of immunoreactivity to the antibodies raised against the phosphorylated NF and SV2 at the nerve terminals in the EDL muscles. Fig. S3 shows Z-stack confocal images of EDL muscles from sham-operated $(\mathbf{A}, \mathbf{C})$ and lumbar sympathectomized (B, D, E) mice. Panels A and B show full co-registration of nonphosphorylated NF (SMI $311 \mathrm{Ab}$ ) plus SV2 Ab (green, AF488) and BGT-680 (blue, cy5.5) at the NMJs; C, D and E show staining of phosphorylated NF (SMI $312 \mathrm{Ab}$ ) ) plus SV2 Ab (green, AF488) and BGT-680 (blue, cy5.5). Immunoreactivity to NF-P and SV2 antibodies is positive in the muscle from a sham mouse (c) and some areas of the muscle 7 days after sympathectomy (D), but negative for NF (SMI 3112) in others (E). Quantification of this analysis shows a significant difference between sham and sympathectomized mice (sham: $98 \pm 1.6$ positive in 105 NMJs in 3 muscles from 3 mice; sympathectomized: $22 \pm 2.7 \%$ positive immunoreactivity in 69 NMJs in 3 muscles from 3 mice; $\mathrm{P}<0.001)$.

This article is protected by copyright. All rights reserved. 
This study does not rule out an increase in PP2A and PP1 phosphatases activity, a role for the calcineurin phosphatase, and/or a decrease in levels of activity of previously identified NF kinases, such as cyclin-dependent protein kinase 5, mitogen-activated protein kinase, casein kinase 1 and 2, and glycogen synthase kinase 3b, ${ }^{55,95}$ in the lower levels of NF phosphorylation in sympathectomized compared to sham-operated mice. That dephosphorylation facilitates NF enzymatic degradation has been reported; ${ }^{96}$ however, we have recorded a significant increase in NF-H and NF-M subunit levels which could be due to the relatively short sympathectomy. It should be notice that the increased susceptibility of dephosphorylated NF to calpain enzymatic degradation has been reported in vitro; ${ }^{96}$ and whether this happens in vivo is unclear.

Our muscle transcriptome analysis shows that after sympathectomy, integrin-linked kinase (ILK) signaling is the most downregulated. It links the extracellular matrix to the actin cytoskeleton ${ }^{97}$ and promotes formation of cell-cell contacts. ${ }^{98,99}$ Integrins are involved in human NF-H phosphorylation ${ }^{100}$ and stimulate phosphorylation of the NF-M subunit KSP repeat motif by activating Erk1/Erk2 in motor neurons. ${ }^{101}$

\section{SNS regulates MuRF1 expression and postsynaptic AChR}

We found an elevation in MuRF1 transcript and protein after SNS ablation. The increase in the E3 ligase led to a decrease in sarcolemmal AChR but an increase in the total amount. MuRF1 is expressed in both type-I and type-II fibers, preferentially in the latter, is highly enriched in the postterminal, interacts with AChR in endocytic structures, ${ }^{68}$ and is involved in muscle trophism and maintenance. ${ }^{102}$ Preferential MuRF1 expression in type-II fibers may account for some discrepancy between measures in GA and TA muscles. Sympathectomized MuRF1KO mice showed AChR partition between the sarcolemma and subsarcolemmal domain similar to that

This article is protected by copyright. All rights reserved. 
observed in innervated young mice. These results support the conclusion that MuRF1 mediates SNS regulation of the fraction of receptors located at the postterminal NMJ.

Sciatic denervation leads to increased MuRF1 and Fbxo32 in the rat, ${ }^{103}$ while MuRF1 but not Fbxo32 (atrogin-1) was significantly altered at day 14 after motor denervation in both soleus and tibialis anterior in the mouse as determined by immunoblot. ${ }^{102}$ In a previous study, ${ }^{44}$ Fbxo32 decreased at day 7 after motor denervation, In response to mouse motor denervation the overexpression of Fbxo32 and MuRF-1 peaked at day 3 and thereafter declined, suggesting that other signaling pathways and other proteolytic mechanisms might become predominant at later times." ${ }^{44}$ Note that treatment with the $\beta 2$-AR agonist clenbuterol prevents denervation-induced increases in Fbxo32 levels. ${ }^{104}$ These data indicate that maintaining sympathetic activity or stimulating $\beta 2$-AR prevents increases in Fbxo32 levels. We analyzed Fbxo32 expression in qPCR studies using primers flanking the E-boxes in the Fbxo32 promoter. ${ }^{70}$ These data show a significant increase of this gene in TA and GA muscles at days 3 and 7 after sympathectomy (Fig. 11).

Whether MuRF1 mediates muscle atrophy in response SNA ablation is controversial. Transgenic muscle-specific overexpression of $M u R F 1$ does not cause muscle atrophy, ${ }^{105}$ but the same group demonstrated that $M u R F 1 \mathrm{KO}$ dramatically prevents denervation-induced atrophy in mouse TA muscle. ${ }^{102}$ More recently, that induction of genes associated with the NMJ is blunted in MuRF1 KO mice has been reported. ${ }^{82}$ Thus, we cannot rule out MuRF1 participation in denervation-induced muscle atrophy.

The increase in MuRF1 after sympathectomy suggests that the SNS inhibits its expression under physiological conditions. We ruled out the participation of several alternative pathways, ${ }^{106}$ and the potential effect of $\beta 2-\mathrm{AR}$ was also excluded because it was increased in the TA but

This article is protected by copyright. All rights reserved. 
produced no significant changes in the GA after SNS ablation. We also found an increase in PKA(RI $\alpha)$ but a decrease in the PKA(RII $\alpha)$ PKA(RI $\alpha)$ ratio, which was recently proposed as a marker of the failure of postsynaptic AChR recycling and membrane insertion. ${ }^{71}$ An alternative mechanism for the elevation of MuRF1 levels after SNS ablation could be decreased muscle autophagy. However, although lysosome degradation of proteasomes has been demonstrated in rat liver ${ }^{107}$ its role in the skeletal muscle is not known.

Impaired motor axon function is further supported by elevated Hdac4 concentration at the NMJ. ${ }^{81,70}$ The Hdac4 gene decreased from day 3 to day 7 after sympathectomy, while the protein remained elevated at day 7. MuRF1 regulation by the canonical $\mathrm{G} \alpha_{\mathrm{i} 2}$-myogenin cascade has been reported, ${ }^{108}$ but whether SNS dysfunction is involved is unknown. We found that sympathectomy downregulates $\mathrm{G} \alpha_{\mathrm{i} 2}$, which has been shown to increase, Hdac4 ${ }^{108}$ and both findings were prevented by infecting the TA muscle with the constitutively activated form of $\mathrm{G \alpha}_{\mathrm{i} 2},{ }^{109}$ which expression was carry out by an adeno-associated virus, $\mathrm{AAV}-\mathrm{G \alpha}_{\mathrm{i} 2}(\mathrm{Q} 205 \mathrm{~L})$. Myogenin induces muscle and serum miR-206, which suppresses $H d a c 4$ and promotes reinnervation. ${ }^{70}$ A role of the SNS denervation of blood vessels in NMJ molecular composition and function cannot be ruled out; however, $\mathrm{G \alpha}_{\mathrm{i} 2}(\mathrm{Q} 205 \mathrm{~L})$ expression specifically in myofibers ${ }^{108}$ is consistent with a direct effect of sympathetic input on NMJs. Also, muscle flow recording has shown that the effect of epinephrine on neuromuscular transmission is independent of concomitant vascular changes produced by the catecholamine. ${ }^{110}$

In summary, the SNS regulates NF phosphorylation, motor axon vesicle release, maintains optimal $\mathrm{Gd}_{\mathrm{i} 2}$ expression and prevents any increase in Hdac4, myogenin, MuRF1, and miR-206. Upregulation of MuRF1 leads to muscle atrophy and downregulation of postsynaptic membrane

This article is protected by copyright. All rights reserved. 
AChR. Our findings are relevant to clinical conditions characterized by progressive decline of sympathetic innervation, such as neurodegenerative diseases and aging sarcopenia.

\section{Materials and Methods}

\section{Animals and ethics statement}

Young (2-3-month-old) male and female C57BL/6 and B6.Cg-Tg(Thy1-YFP)16Jrs/J mice were obtained from the National Institute on Aging (NIA) and Jackson Laboratory (Stock No: 003709), respectively, and along with the MuRF-1(Trim63)-KO mice (our colony) ${ }^{111}$ were housed in the pathogen-free Animal Research Program (ARP) of the Wake Forest School of Medicine (WFSM) at $20-23^{\circ} \mathrm{C}$ and a $12: 12$-hour dark-light cycle. All mice were fed chow ad libitum and had continuous access to drinking water. All experimental procedures were conducted in compliance with National Institutes of Health laboratory animal care guidelines. We made every effort to minimize mouse suffering. The protocol A15-219 was approved by the WFSM Institutional Animal Care and Use Committee for this study.

\section{Surgical sympathectomy and experiment recording times}

Mice were anesthetized with $2 \%$ inhaled isoflurane. Microsurgical bilateral excision of the second and third lumbar (L2-L3) ganglia of the paravertebral sympathetic chain (Fig. 1A) involved opening the ventral abdominal wall, retracting the organs laterally, identifying paravertebral structures, including the sympathetic ganglia chain, aorta, and renal arteries; and excising the ganglia. ${ }^{12-115}$ Tibialis anterior (TA), gastrocnemius (GA), soleus, EDL, and lumbricalis muscles did not exhibit $\mathrm{TH}+$ immunoreactivity 7 days after sympathectomy, which indicates that these muscles do not receive sympathetic innervation from the paravertebral sympathetic ganglia other than L2-L3. Ganglia were cryopreserved and stored in Tissue-Tek ${ }^{\circledR}$

This article is protected by copyright. All rights reserved. 
O.C.T. (optimal cutting temperature) compound (Sakura Finetek, Torrance, CA, USA) at $-80^{\circ} \mathrm{C}$. Control mice were subjected to sham operation, consisting of all the previous steps but omitting sympathetic ganglia removal. Sham and sympathectomized mice were anesthetized for the same average time. Most experiments were performed 7 days after sympathectomy or sham operation. However, Figure 11 includes data collected on day 3, and Figures S6-S7 show data collected on days 7 and 14 after surgery, as indicated. The rationale for using these specific timepoints is explained for each set of experiments.

\section{Chemical sympathectomy}

For chemical sympathectomy, 6-hydroxydopamine (6(OH)DA, Sigma-Aldrich, St. Louis, MO) was diluted in $0.3 \%$ ascorbic acid in sterile oxygen-free water. Since IV administration for more than a week resulted in deterioration of overall health status, $6(\mathrm{OH}) \mathrm{DA}(100 \mathrm{mg} / \mathrm{kg})$ or vehicle alone were intramuscularly injected into the hindlimb of 2-month-old C57BL/6 mice every other day for one or two weeks. Oxygen-free water was obtained by gassing water with $\mathrm{N}_{2}$ for 20 min. 116 All solutions were prepared fresh before injection.

\section{Cholera toxin injection and sympathetic ganglia immunohistochemistry}

TA and GA muscles were injected with $4 \mu 1$ cholera toxin subunit B (CTB)-conjugated Alexa Fluor ${ }^{\circledR} 488(1 \mu 1 / \mu 1)$ and $4 \mu$ l CTB-conjugated Alexa Fluor ${ }^{\circledR} 555(5 \mu 1 / \mu 1)$, respectively. The next day, mice were anaesthetized by intraperitoneal injection of a ketamine/xylazine mixture ( $1 \mathrm{ml}$ ketamine $+0.2 \mathrm{ml}$ xylazine $+8.8 \mathrm{ml} \mathrm{H}_{2} \mathrm{O}$ ) and transcardially perfused with $2 \%$ paraformaldehyde (PFA) in 0.1M sodium phosphate buffer solution (pH 7.4). TA, GA, and L2L3 sympathetic ganglia were removed and cryopreserved by sucrose treatment; then O.C.T. was

This article is protected by copyright. All rights reserved. 
embedded, and they were sliced with a cryostat to obtain $10-15 \mu \mathrm{m}$ tissue sections. Figure 1B-D represents three independent experiments.

\section{Sympathetic ganglia immunohistochemistry}

Sympathetic ganglia were pinned in a dish coated with Sylgard 184 silicone (Dow Corning, Midland, MI), fixed in $2 \% \mathrm{PFA}$ at $4{ }^{\circ} \mathrm{C}$ overnight, cryopreserved with increasing concentrations of sucrose ( $5 \%$ at $4{ }^{\circ} \mathrm{C}$ overnight, $20 \%$ at $4{ }^{\circ} \mathrm{C}$ overnight, and $30 \%$ at room temperature for $6 \mathrm{~h}$ ), rinsed in PBS, and frozen in O.C.T. Cryosections $(10-15 \mu \mathrm{m})$, mounted on a glass slide, were rinsed in PBST and blocked with $1 \%$ Triton and $10 \%$ goat serum in PBS at $4{ }^{\circ} \mathrm{C}$ overnight.

Ganglia were labeled with primary rabbit anti-TH polyclonal antibody (AB152, dilution 1:100; Millipore, Billerica, MA) in the presence of $4 \%$ goat serum and $1 \%$ Triton in PBS at $4{ }^{\circ} \mathrm{C}$ overnight. Next day, the preparation was washed in PBST and the secondary AF568 goat antirabbit IgG antibody (A-11036, dilution 1:1000, ThemoFisher; Waltham, MA) added and incubated at $4^{\circ} \mathrm{C}$ overnight. Next day, the preparation was washed with PBST, the nuclei labeled with Hoechst 33342 (H3570, dilution 1:2000, Invitrogen, Carlsbad, CA) at room temperature for 5min, washed in PBS and mounted using mounting medium (S3023, Dako, Carpinteria, CA)

(Fig. 1B-D). Fluorescently labeled ganglia were imaged on an inverted, motorized, fluorescent microscope (Olympus, IX81, Tokyo, Japan) with an Orca-R2 Hamamatsu CCD camera (Hamamatsu, Japan). The camera driver and image acquisition were controlled with a MetaMorph Imaging System (Olympus).

This article is protected by copyright. All rights reserved. 


\section{$T A, G A$, and EDL skeletal muscle histochemical and immunofluorescence}

Skeletal muscle histochemical and immunofluorescence analysis followed reported procedures. ${ }^{45,117} \mathrm{TA}, \mathrm{GA}$ and EDL muscles were used for these experiments due to their distinct fiber type composition, and larger size than lumbricalis, a muscle extensively used in this study. Briefly,

muscles were dissected, perpendicularly stuck to a plastic surface by means of O.C.T thickened with baby powder, quickly frozen in liquid nitrogen, and stored at $-80{ }^{\circ} \mathrm{C}$ until cut into $10-\mu \mathrm{m}$ sections at $-20^{\circ} \mathrm{C}$ with a Leitz cryostat (Buffalo Grove, IL).

To obtain consistent fiber counting across muscles and mice, we serially sectioned the muscle at the main CSA as determined macroscopically then confirmed the largest CSA in the serially mounted hematoxylin- and eosin-stained slices microscopically. The microscopic approach used the Nanozoomer Olympus Microscope, a digital image stitching system. Here, we reported the myofibers counted at the largest CSA.

For immunofluorescence, cryosections were rinsed in phospho-buffered saline (PBS) and blocked with 10\% goat serum in PBS for 1 hour. Myofiber subtypes were identified with specific myosin heavy chain (MHC) isoform antibodies and immunofluorescence microscopy. Muscle sections were incubated with primary mouse antibodies BA-F8 (MHC type-I, dilution: 1: 50), SC-71 (MHC type-IIa, dilution: 1:500), BF-F3 (MHC type-IIb, dilution: 1:100), and 10\% goat serum in PBS for 2 hours at room temperature. All primary antibodies were purchased from the University of Iowa Developmental Studies Hybridoma Bank (DSHB). After washing the sections with PBS twice for 5 minutes, they were incubated with secondary goat anti-mouse antibodies AF350 IgG2b (against BA-F8,1:500), AF488 IgG (1SC-71, 1:500), and AF555 IgM (BF-F3, 1:500) in 10\% goat serum in PBS for 1 hour at room temperature followed by two 5-minute washes with PBS. All secondary antibodies were purchased from Invitrogen (Thermo Fisher,

This article is protected by copyright. All rights reserved. 
Carlsbad, CA). Tissue sections were mounted using fluorescence mounting medium and visualized with an IX81 Olympus fluorescence microscope. Fibers negative to these three antibodies (black) were labeled IIx as reported previously. ${ }^{45}$ Unfortunately, commercially available antibodies against type IIx did not work convincingly in our hands.

\section{Neurofilament and neuromuscular junction immunostaining in lumbricalis muscles}

For these experiments, we took advantage of the anatomical organization of the lumbricalis into few myofiber layers, which allowed us to fully image the intact muscle and assess muscle fiber innervation avoiding cryosection distortions. Lumbricalis muscles were dissected, freed from surrounding tissues, the tendons pinned in a Sylgard coated dish, fixed in $2 \%$ PFA at $4{ }^{\circ} \mathrm{C}$ overnight, washed in PBST for 10 min three times, and blocked with $1 \%$ Triton and $10 \%$ goat serum in PBS at $4^{\circ} \mathrm{C}$ overnight. Next day the muscle was incubated in nonphosphorylated SMI311 (cat \#837801, dilution:1:500, Biolegend, San Diego, CA) or phosphorylated nerve neurofilament SMI-312 (cat \#837901, dilution: 1:500, Biolegend), plus synaptic vesicle protein 2 (cat. SV2, dilution: 1:10, DSHB), and $\alpha$-bungarotoxin (BGT) CF680R (cat \#00003, dilution: 1:250, Biotium, Fremont, CA) in $1 \%$ Triton and $4 \%$ goat serum in PBS at $4^{\circ} \mathrm{C}$ overnight. Next day, the preparation was washed 3 times in PBST for $1 \mathrm{~h}$ each. An AF568 goat anti-mouse IgG (cat \#A11004, dilution: 1:1000, ThermoFisher), used as the secondary antibody for SMI-311, SMI-312, and SV2, plus 1\% goat serum and BGT CF680R were added at room temperature for 4h. The preparation was washed 3 times in PBS for $1 \mathrm{~h}$ each, tendons were cut, the lumbricalis muscle mounted on a glass slide using Dako mounting medium, and visualized with an Olympus IX81 fluorescence microscope or an Olympus FV1200/IX83 spectral laser scanning confocal microscope.

This article is protected by copyright. All rights reserved. 


\section{NMJ preterminal and postterminal area and quantification of the fractional occupancy of}

\section{postsynaptic endplates}

The NMJ postterminal area was calculated by manually outlining the borders of the BGT+ pretzel shape and converting squared pixels to squared microns using MetaMorph or Image-J Imaging software. Similarly, the preterminal area was calculated by outlining SV2 or synaptophysin (ab32127antibody (Abcam, Cambridge, MA, USA) positive zones. We quantified the fractional occupancy of postsynaptic endplates using SV2 or synaptophysin immunoreactivity overlapping the postterminal BGT + area. Identity of experimental groups was blinded to the investigator.

\section{Modified iDisco clearing technique}

For lumbricalis muscle immunofluorescence as shown in Fig. 3B and video 1, muscles were treated with a modified iDisco technique. ${ }^{31,118}$ Muscles, pinned in a Sylgard coated dish, were fixed in $4 \%$ PFA at $4{ }^{\circ} \mathrm{C}$ overnight. Next day, muscles were washed three times with PBS in $1 \mathrm{~h}$ and preincubated with $0.2 \%$ Triton $\mathrm{X}-100 / 20 \%$ (vol/vol) DMSO/ $0.3 \mathrm{M}$ glycine in $\mathrm{PBS}$ at $37{ }^{\circ} \mathrm{C}$ overnight. Muscles were then incubated in $0.2 \%$ Tween in PBS with $10 \mu \mathrm{g} / \mathrm{ml}$ heparin (PTwH) at room temperature for 2 days and then blocked with $0.2 \%$ Triton $\mathrm{X}-100 / 10 \%$ (vol/vol) DMSO/6\% (vol/vol) BSA in PBS (PTDB solution) at $37^{\circ} \mathrm{C}$ for $24 \mathrm{~h}$. Muscles were washed three times with PTwH in $1 \mathrm{~h}$, followed by incubation with primary (rabbit anti-TH polyclonal antibody, AB152, dilution 1:100; Millipore) and secondary (AF594 donkey anti-rabbit IgG antibody, R37119, dilution 1:1000, ThemoFisher) antibodies in PTDB solution (diluted with PTwH) for 4 days each. Postterminals were stained with BGT CF680R, added together with secondary antibody. Between primary and secondary antibody staining, muscles were washed 
with PTwH solution for 2 days and again 2 days before imaging. Muscles were mounted on a glass slide using Dako mounting medium.

\section{Electron microscopy, myelin staining with toluidine blue, and neurofilament distances quantification}

Lumbricalis muscles, pinned to a Sylgard coated dish at slack length, were fixed in vitro in $0.5 \%$ glutaraldehyde $-4 \%$ PFA in PBS for 30-60 min. In our hands, this fixation procedure and cardiac perfusion and fixation do not differ in terms of preparation quality. Due to the particular arrangement of the NMJs, we excised a band of muscle equidistant from both tendons and further processed for electron microscopy. In addition, tibioperoneal nerves were fixed in $2.5 \%$ glutaraldehyde, placed in 1\% osmium tetroxide, dehydrated through a graded series of ethanol and propylene oxide cut at $0.39 \mu \mathrm{m}$, and stained with toluidine blue. Images were obtained using an FEI Tecnai BioTwin transmission electron microscope (120 keV; ThermoFisher).

The distance between NFs in transmission electron micrographs of nerve transversal sections was measured using the Nearest Neighbor Distances Calculation ${ }^{64,65}$ plugin for Image-J software.

\section{Electrophysiological recording of neuromuscular transmission}

Surgical sympathectomized and sham mice were sacrificed 7 days after surgery, and the lumbricalis muscle was dissected with its plantar nerve attached (Fig. 1E). The neuromuscular preparation was incubated in $\mu$-conotoxin GIIIB (Alomone Labs, Jerusalem, Israel) to a final concentration of $1 \mu \mathrm{M}$ for 30 minutes to prevent muscle contraction. The NMJ transmission was then recorded intracellularly in oxygenated normal mammalian Ringer's solution (in mM, 135

This article is protected by copyright. All rights reserved. 
$\mathrm{NaCl}, 5 \mathrm{KCl}, 1 \mathrm{MgSO}_{4}, 15 \mathrm{NaHCO}_{3}, 1 \mathrm{Na}_{2} \mathrm{HPO}_{4}, 11$ D-glucose, 2.5 calcium gluconate, $\mathrm{pH} 7.4$ ) using a TEV-200A amplifier (Dagan Co., Minneapolis, MN), DigiData 1322A, and pClamp10.5 software (MDS Analytical Technologies, Sunnyvale, CA). The intracellular electrodes ( $40 \mathrm{~m} \Omega$ ) were filled with $2 \mathrm{M} \mathrm{K}$-citrate and $10 \mathrm{mM} \mathrm{K}$-chloride and mounted on the stage of a MP-285 micromanipulator (Sutter Instruments, Novato, CA). An upright, fixed-stage Zeiss Axioscope FS microscope (Carl Zeiss, Thornwood, NY) with a 10 or 20X, water immersion FLUAR objective (Zeiss), mounted on a microscope translator (Sutter Instruments), was used to visualize the preparation. We recorded miniature endplate potentials (MEPPs) and evoked endplate potentials (EPPs) in an average of 15 NMJs per mouse. The proximity of the recording microelectrode to the NMJ was established microscopically and by the amplitude of MEPPs. EPPs were elicited by electrical stimulation at increasing frequencies from 2 to $150 \mathrm{~Hz}$. EPP facilitation and depression were measured as the ratio between the maximum and the first EPP amplitudes and between the first and the last EPP of the run, respectively. MEPPs were baseline corrected, and their amplitude, frequency, time-to-peak, half-decay time, and duration were retrieved by setting basic selection criteria to conduct peak selection. Quantal content was calculated by dividing the mean amplitude of the EPP by the mean amplitude of the MEPPs as described. ${ }^{49}$

\section{Assessment of muscle force generated by direct muscle- or nerve-evoked stimulation}

We recorded nerve-evoked muscle contraction at increasing frequencies $(2-150 \mathrm{~Hz})$ for $1 \mathrm{~s}$ in sympathectomized and sham mice using an Aurora Scientific 407A force transducer and stimulator. We then blocked neuromuscular transmission with $10^{-5} \mathrm{~g} / \mathrm{ml}$ d-tubocurarine. After verifying that nerve stimulation evoked no detectable muscle contraction, we switched to direct muscle force recording, using field stimulation generated between two parallel platinum plates,

This article is protected by copyright. All rights reserved. 
and repeated maximal subtetanic and tetanic forces at the same frequencies in lumbricalis

muscle. The composition of the bath solution was the same used for NMJ transmission recordings. The experiment was carried out at room temperature $\left(\sim 21^{\circ} \mathrm{C}\right)$.

\section{Protein isolation and immunoblots}

Total and membrane acetylcholine receptor pull-down and immunoblot. To isolate the total cytosolic AChR fraction, frozen muscles were mechanically disrupted using a mortar and pestle in liquid nitrogen and handheld Tissue-Tearor ${ }^{\mathrm{TM}}$ in ice-cold RIPA ${ }^{\circledR}$ buffer (Sigma-Aldrich, St. Louis, MO) plus Roche complete Mini Protease Inhibitor Cocktail from Thermo Fisher Scientific. The resulting homogenate was centrifuged at $18,000 \mathrm{~g}$ for $10 \mathrm{~min}$ at $-4^{\circ} \mathrm{C}$ to remove insoluble debris, and the total amount of protein in the supernatant was measured.

BiotinXX-BGT (Thermo Fisher) was added to the proteins to start total AChR pull-down, which was completed overnight with NeutroAvidin beads (Thermo Fisher). SDS-PAGE was conducted using a 4-20\% gradient gel in a Mini-PROTEAN gel system (Bio-Rad Laboratories, Hemel Hempstead, Herts, UK). Gels were then transferred to $0.45 \mu \mathrm{m}$ pore size PVDF membranes (Millipore, Billerica, MA). For primary antibody incubation, blots were blocked in 5\% nonfat dry milk with $0.1 \%$ TWEEN in tris-buffered saline (TBS, $150 \mathrm{mM} \mathrm{NaCl}, 50 \mathrm{mM}$ Tris$\mathrm{HCl}, \mathrm{pH}$ 7.5). An anti-AChR $\alpha 1$ primary (Biolegend, San Diego, CA) and anti-rat horseradish peroxidase (HRP) secondary antibody Jackson Immunoresearch, West Grove, PA) were used. GAPDH was used as the loading control and its levels were determined by immunoblotting the protein lysate with a GAPDH antibody (cat \#GTX627408, 1:40,000, Genetex, Irvine, CA) and an anti-mouse HRP secondary antibody (Amersham). ${ }^{119}$

This article is protected by copyright. All rights reserved. 
To measure membrane AChR fraction, we initially injected increasing concentrations of bungarotoxin-biotin (2-4 $\mu \mathrm{g}$ ) in different mice (weight: $20 \pm 0.5 \mathrm{~g}$ ) to determine the saturating dose $(3 \mu \mathrm{g})$, which was defined as that providing the maximal immunoblot signal. As expected, the saturating dose was close to the lethal dose $(4 \mu \mathrm{g})$ and was systematically injected into the TA muscles of sympathectomized or sham mice. Mice were sacrificed $6 \mathrm{~h}$ later, and the TA and GA muscles was dissected and processed as described above for AChR quantification. Peroxidase activity was measured with the Amersham ECL plus western blot detection reagents (GE Healthcare, Piscataway, NJ), and band intensity was measured using a Kodak Gel Doc imaging system (Carestream Health, Inc., Rochester, NY) or NIH ImageJ software.

Protein measures in muscle lysates. For the remaining proteins analyzed in skeletal muscle lysates, we used the primary antibodies listed in Table S1. Amersham horse-radish-peroxidaseconjugated secondary antibodies were purchased from GE Healthcare Life Sciences (Pittsburgh, PA).

\section{Real-time PCR (qPCR) mRNA}

Messenger RNA-expression levels were quantified by qPCR using a SensiFAST Probe Lo-ROX One-Step Kit (Bioline, Taunton, MA). Total RNA (20ng) was loaded for qPCR in $20-\mu 1$ total volume. After RT cDNA synthesis at $45^{\circ} \mathrm{C}$ for 30 minutes and RT deactivation at $95{ }^{\circ} \mathrm{C}$ for 5 minutes, PCR was performed over 40 cycles at $95^{\circ} \mathrm{C}$ for 10 seconds and $60{ }^{\circ} \mathrm{C}$ for 1 minute. Results were normalized to glyceraldehyde 3-phosphate dehydrogenase (Gapdh) RNA as the internal control. Relative quantities were calculated using the comparative threshold $\left(C_{\mathrm{T}}\right)$

method. ${ }^{120,121}$ All samples were run in triplicate. Primers and Taqman probes were purchased

This article is protected by copyright. All rights reserved. 
from Applied Biosystems (Foster City, CA). For a complete list of the Taqman primers used for skeletal muscle and nerve mRNA analysis, see Table S2.

\section{Muscle and serum miR-206}

TA and GA muscle miR-206 was measured using the miRNeasy Mini Kit (cat. \#217004 for muscle and \#217184 for serum) from Qiagen Inc. (Valencia, CA), followed by a TaqMan Advance miRNA cDNA synthesis Kit (A28007), and qPCR using TaqMan Fast Advanced Master Mix (4444556) and the primer mmu_miR-206-3p (mm481645_mir). Has-miR-16-5p (477860_mir) was used as an endogenous control (ThermoFisher) for both muscle and serum determinations.

\section{Microarray Data Processing and Analysis}

Total RNA from GA muscle was obtained using the RNeasy Mini Kit (Qiagen) and measured with Eukaryote Total RNA Nano-assay (2,100 Expert). High-quality RNA (RIN $>8)$ was hybridized to a mouse MG-430 GeneAtlas array strip (Affymetrix ${ }^{\mathrm{TM}}$, Santa Clara, CA) according to the standard protocols of the Wake Forest Comprehensive Cancer Center Microarray Core. Four biological replicates for sympathectomized and sham mice were used. Briefly, we carried out quality control and normalization procedures using the Simpleaffy package from R/Bioconductor. ${ }^{122}$ We used the Robust Multichip Average algorithm for background adjustment, quantile normalization, and to summarize probe set values. ${ }^{123}$ Statistical analysis and heat-map visualization of differentially expressed transcripts relied on MultiExperiment Viewer software $(\mathrm{MeV} 4.9) .{ }^{124} \mathrm{P}<0.05$ was considered significant. For automated functional annotation and gene-enrichment analysis, we used the EnrichR tool, which calculates

This article is protected by copyright. All rights reserved. 
overrepresentation of specific biological themes and pathways in relation to the total number of genes assayed and annotated. We also employed ClueGO and CluePedia Cytoscapes plug-in and Ingenuity Pathway Analysis (IPA) resources for functional enrichment analysis and genep/pathway network visualization of changes in gene expression.

\section{Adeno-Associated Virus (AAV) Construct for in vivo $G \alpha_{i 2}$ Overexpression}

For expression in vivo, the human $\mathrm{G \alpha}_{\mathrm{i} 2}(\mathrm{Q} 205 \mathrm{~L})$ mutant was subcloned into a viral vector driving EGFP and $\mathrm{G \alpha}_{\mathrm{i} 2}(\mathrm{Q} 205 \mathrm{~L})$ expression under two independent CMV promoters. The vectors were packaged in AAV serotype-2 by transfection in human embryonic kidney (HEK)293 cells by Welgen Inc. (Worcester, MA). ${ }^{108}$ Viral infections were performed through TA injection of $10^{10}$ genome copies of $\mathrm{AAV}-\mathrm{G} \alpha_{\mathrm{i} 2}(\mathrm{Q} 205 \mathrm{~L})$ under isoflurane anaesthesia at time zero and week 2 , followed by sympathectomy and mouse euthanasia on week 3 and 4 , respectively. TA muscles were rapidly dissected and snap frozen for protein analysis.

\section{Statistical analysis}

All experiments and analyses were conducted blind to treatment group. No statistical methods were used to predetermine sample sizes; however, our sample sizes are similar to those reported in recently published studies. ${ }^{71,125}$ Sigma Plot, version 12.5 (Systat Software, Inc., San Jose, CA), and Microsoft Excel software were used for statistical analysis. All data were expressed as mean \pm S.E.M. Student's t-test was used to compare two groups (data included in Figs. 2-7, 9bd, 11, S3-S7), Exact Mann-Whitney Rank Sum Test to test the data included in Fig. 5i-l, and Analysis of Variance (ANOVA) followed by Bonferroni's post hoc analysis to compare three or more groups as in Figs. 8, 9A, and 10. A $p$-value $<0.05$ was considered significant.

This article is protected by copyright. All rights reserved. 


\section{Acknowledgements}

We would like to thank Drs. Richard R. Ribchester, the University of Edinburg, and Michael L. Garcia, University of Missouri, for their useful comments during the development of this project, Blake Nayland, Wake Forest (WF) University, Neuroscience Program, for helping with data analysis, Lou Craddock and Dr. Jeff Chou from the WF Comprehensive Cancer Center Genomics Share Resource-Microarray Core Lab for assistance with RNA microarray processing and analysis. Kenneth Gran, the WF Comprehensive Cancer Center, and Kelly Pace, WF Baptist Medical Center, Department of Pathology, helped with confocal and electron microscopy and Forensic Photography, respectively. This research was supported by the National Institutes of Health grants and R01AG013934, R01AG057013 and R01AG057013-02S1 to O.D. and the WF Claude D. Pepper Older Americans Independence Center (P30-AG21332) Pilot Project to O.D., and R01HL104129 to M.W.

\section{Conflict of interest}

The authors declare that they have no conflict of interest

This article is protected by copyright. All rights reserved. 


\section{References}

1. Jensen-Daham C, Waldemar G, Jensen TS, et al. Autonomic Dysfunction in Patients with Mild to Moderate Alzheimer's Disease. J Alzheimers Dis. 2015;47:681-689.

2. Low PA, Bennarroch EE. Clinical Autonomic Disorders. 3rd ed: Lippincott Williams \& Wilkins; 2008.

3. Okamoto LE, Biaggioni I. Chronic fatigue syndrome and the autonomic nervous system. In: Robertson D, Biaggioni, I., Burnstock, G., Low, P.A., Paton, JF.R., ed. Primer on the Autonomic Nervous System. 3rd ed. Amsterdam: Academic; 2012:531-534.

4. Tachi N, Ohya K, Chiba S, Nihira H, Minagawa K. Muscle involvement in congenital insensitivity to pain with anhidrosis. Pediatr Neurol. 1995;12(3):264-266.

5. Munver R, Volfson IA. Adrenal insufficiency: diagnosis and management. Curr Urol Rep. 2006;7(1):80-85.

6. Janig W. Complex regional pain syndrome. 3rd ed. Amsterdam: Academic; 2012.

7. Femminella GD, Rengo G, Komici K, et al. Autonomic dysfunction in Alzheimer's disease: tools for assessment and review of the literature. J Alzheimers Dis. $2014 ; 42(2): 369-377$

8. Orimo S, Kanazawa T, Nakamura A, et al. Degeneration of cardiac sympathetic nerve can occur in multiple system atrophy. Acta Neuropathol. 2007;113(1):81-86.

9. Ooi W, Barrett S, Hossain M, Kelley-Gagnon M, Lipsitz LA. PAtterns of orthostatic blood pressure change and their clinical correlates in a frail, elderly population. JAMA. 1997;277(16):1299-1304.

This article is protected by copyright. All rights reserved. 
10. Mu L, Sobotka S, Chen J, et al. Altered pharyngeal muscles in Parkinson disease. $J$ Neuropathol Exp Neurol. 2012;71(6):520-530.

11. Bloch A, Probst A, Bissig H, Adams H, Tolnay M. Alpha-synuclein pathology of the spinal and peripheral autonomic nervous system in neurologically unimpaired elderly subjects. Neuropathol Appl Neurobiol. 2006;32(3):284-295.

12. Cano-Jaimez M, Pérez-Sánchez F, Milán M, Buendía P, Ambrosio S, Fariñas I. Vulnerability of peripheral catecholaminergic neurons to MPTP is not regulated by $\alpha$ synuclein. Neurobiol Dis. 2010;38(1):92-103.

13. Kandinov B, Korczyn AD, Rabinowitz R, Nefussy B, Drory VE. Autonomic impairment in a transgenic mouse model of amyotrophic lateral sclerosis. Auton Neurosci. 2011;159(1-2):84-89.

14. Askmark H, Eeg-Olofsson K, Johansson A, Nilsson P, Olsson Y, Aquilonius S. Parkinsonism and neck extensor myopathy: A new syndrome or coincidental findings? Arch Neurol. 2001;58(2):232-237.

15. O'Suilleabhain P, Low PA, Lennon VA. Autonomic dysfunction in the Lambert-Eaton myasthenic syndrome: serologic and clinical correlates. Neurology. 1998;50(1):88-93.

16. Lindquist S, Stangel M. Update on treatment options for Lambert-Eaton myasthenic syndrome: focus on use of amifampridine. Neuropsychiatr Dis Treat. 2011;7:341-349.

17. Van Cauwenbergh D, Nijs J, Kos D, Van Weijnen L, Struyf F, Meeus M. Malfunctioning of the autonomic nervous system in patients with chronic fatigue syndrome: a systematic literature review. Eur J Clin Invest. 2014;44(5):516-526.

This article is protected by copyright. All rights reserved. 
18. Beitzel F, Sillence MN, Lynch GS. beta-Adrenoceptor signaling in regenerating skeletal muscle after beta-agonist administration. Am J Physiol Endocrinol Metab. 2007;293(4):E932-940.

19. Le Panse B, Arlettaz A, Portier H, Lecoq AM, De Ceaurriz J, Collomp K. Effects of acute salbutamol intake during supramaximal exercise in women. Br J Sports Med. 2007;41(7):430-434.

20. Lipsitz LA, Novak V. Aging and autonomic function. Third ed. Rochester: Mayo Foundation; 2008.

21. Delbono O. Neural Control of Aging Skeletal Muscle. Aging Cell. 2003;2:21-29.

22. Gonzalez-Freire M, de Cabo R, Studenski S, Ferrucci L. The Neuromuscular Junction (NMJ): aging at the crossroad between nerves and muscle. Front Aging Neurosci. 2014;6.

23. Boeke J. Ueber eine aus marklosen Fasern hervorgehende zweite Art von hypolemmalen Nervenendplatten bei den quergestreiften Muskelfasern der Vertebraten. Anat Anz. 1909;35:481-484.

24. Boeke J. Die motorische Endplatte bei den höheren Vertebraten, ihre Entwickelung, Form und Zusammenhang mit der Muskelfaser. Anat Anz. 1909;35:240-256.

25. Boeke J. Die doppelte (motorische und sympathische) efferente innervation der quergestreiften muskelfasern. Anat Anz. 1913;44:343-356.

26. Kuba K. Effects of catecholamines on the neuromuscular junction in the rat diaphragm. $J$ Physiol. 1970;211(3):551-570.

27. Hunter JI. Lectures ON THE SYMPATHETIC INNERVATION OF STRIATED MUSCLE. Br Med J. 1925;1(3344):197-201.

This article is protected by copyright. All rights reserved. 
28. Ackerknecht EH. The history of the discovery of the vegatative (autonomic) nervous system. Med Hist. 1974;18(1):1-8.

29. Langley JN, Anderson HK. The union of different kinds of nerve fibres. $J$ Physiol. 1904;31(5):365-391.

30. Wigston DJ, Sanes JR. Selective reinnervation of intercostal muscles transplanted from different segmental levels to a common site. $J$ Neurosci. 1985;5(5):1208-1221.

31. Khan MM, Lustrino D, Silveira WA, et al. Sympathetic innervation controls homeostasis of neuromuscular junctions in health and disease. Proc Natl Acad Sci. 2016;113(3):746750.

32. Griffin JW, Thompson WJ. Biology and pathology of nonmyelinating Schwann cells. Glia. 2008;56(14):1518-1531.

33. Barker D, Saito M. Autonomic innervation of receptors and muscle fibres in cat skeletal muscle. Proc R Soc London B. 1981;212(1188):317-332.

34. Eichmann A, Brunet I. Arterial Innervation in Development and Disease. Sci Transl Med. 2014;6(252):252ps259-252ps259.

35. Lynch GS, Ryall JG. Role of beta-adrenoceptor signaling in skeletal muscle: implications for muscle wasting and disease. Physiol Rev. 2008;88(2):729-767.

36. Howard JF, Jr. Adverse drug effects on neuromuscular transmission. Semin Neurol. 1990;10(1):89-102.

37. Lorenzoni PJ, Scola RH, Kay CSK, et al. Salbutamol therapy in congenital myasthenic syndrome due to DOK7 mutation. J Neurol Sci. 2013;331(1-2):155-157.

38. Baker DJ, Constantin-Teodosiu D, Jones SW, Timmons JA, Greenhaff PL. Chronic treatment with the beta(2)-adrenoceptor agonist prodrug BRL-47672 impairs rat skeletal

This article is protected by copyright. All rights reserved. 
muscle function by inducing a comprehensive shift to a faster muscle phenotype. $J$ Pharmacol Exp Ther. 2006;319(1):439-446.

39. Stanke M, Duong CV, Pape M, et al. Target-dependent specification of the neurotransmitter phenotype: cholinergic differentiation of sympathetic neurons is mediated in vivo by gp130 signaling. Development. 2006;133(1):141-150.

40. Koblinger K, Fuzesi T, Ejdrygiewicz J, Krajacic A, Bains JS, Whelan PJ. Characterization of A11 neurons projecting to the spinal cord of mice. PLoS One. 2014;9(10):e109636.

41. Radovanovic D, Peikert K, Lindström M, Domellöf FP. Sympathetic innervation of human muscle spindles. $J$ Anat. 2015;226(6):542-548.

42. Chan-Palay V, Engel AG, Wu JY, Palay SL. Coexistence in human and primate neuromuscular junctions of enzymes synthesizing acetylcholine, catecholamine, taurine, and gamma-aminobutyric acid. Proc Natl Acad Sci U S A. 1982;79(22):7027-7030.

43. Kerman IA, Enquist LW, Watson SJ, Yates BJ. Brainstem substrates of sympatho-motor circuitry identified using trans-synaptic tracing with pseudorabies virus recombinants. $J$ Neurosci. 2003;23(11):4657-4666.

44. Raffaello A, Laveder P, Romualdi C, et al. Denervation in murine fast-twitch muscle: short-term physiological changes and temporal expression profiling. Physiol Genomics. 2006;25(1):60-74.

45. Bloemberg D, Quadrilatero J. Rapid determination of myosin heavy chain expression in rat, mouse, and human skeletal muscle using multicolor immunofluorescence analysis. PLoS One. 2012;7(4):e35273.

This article is protected by copyright. All rights reserved. 
46. Wiberg R, Jonsson S, Novikova LN, Kingham PJ. Investigation of the Expression of Myogenic Transcription Factors, microRNAs and Muscle-Specific E3 Ubiquitin Ligases in the Medial Gastrocnemius and Soleus Muscles following Peripheral Nerve Injury. PLOS ONE. 2015;10(12):e0142699.

47. Gu Y, Hall ZW. Characterization of acetylcholine receptor subunits in developing and in denervated mammalian muscle. J Biol Chem. 1988;263(26):12878-12885.

48. Merlie JP, Mudd J, Cheng TC, Olson EN. Myogenin and acetylcholine receptor alpha gene promoters mediate transcriptional regulation in response to motor innervation. $J$ Biol Chem. 1994;269(4):2461-2467.

49. Sugiura Y, Chen F, Liu Y, Lin W. Electrophysiological Characterization of Neuromuscular Synaptic Dysfunction in Mice. In: Manfredi G, Kawamata H, eds. Neurodegeneration. Vol 793. Humana Press; 2011:391-400.

50. Feng G, Mellor RH, Bernstein M, et al. Imaging Neuronal Subsets in Transgenic Mice Expressing Multiple Spectral Variants of GFP. Neuron. 2000;28(1):41-51.

51. Hisanaga S, Hirokawa N. The effects of dephosphorylation on the structure of the projections of neurofilament. J Neurosci. 1989;9(3):959-966.

52. Hisanaga S, Hirokawa N. Dephosphorylation-induced interactions of neurofilaments with microtubules. J Biol Chem. 1990;265(35):21852-21858.

53. Lewis SE, Nixon RA. Multiple phosphorylated variants of the high molecular mass subunit of neurofilaments in axons of retinal cell neurons: characterization and evidence for their differential association with stationary and moving neurofilaments. $J$ Cell Biol. 1988;107(6 Pt 2):2689-2701.

This article is protected by copyright. All rights reserved. 
54. Maday S, Twelvetrees AE, Moughamian AJ, Holzbaur ELF. AXONAL TRANSPORT: CARGO-SPECIFIC MECHANISMS OF MOTILITY AND REGULATION. Neuron. 2014;84(2):292-309.

55. Hoffman A, Taleski G, Sontag E. The protein serine/threonine phosphatases PP2A, PP1 and calcineurin: A triple threat in the regulation of the neuronal cytoskeleton. $\mathrm{Mol} \mathrm{Cel}$ Neurosci. 2017;84:119-131.

56. Rao MV, Mohan PS, Kumar A, et al. The myosin Va head domain binds to the neurofilament-L rod and modulates endoplasmic reticulum (ER) content and distribution within axons. PLoS One. 2011;6(2):e17087.

57. Yuan A, Sershen H, Veeranna, et al. Neurofilament subunits are integral components of synapses and modulate neurotransmission and behavior in vivo. Mol Psychiatry. 2015;20(8):986-994.

58. Khan MM, Strack S, Wild F, et al. Role of autophagy, SQSTM1, SH3GLB1, and TRIM63 in the turnover of nicotinic acetylcholine receptors. Autophagy. 2014;10(1):123136.

59. Pang DT, Wang JK, Valtorta F, Benfenati F, Greengard P. Protein tyrosine phosphorylation in synaptic vesicles. Proc Natl Acad Sci U S A. 1988;85(3):762-766.

60. Barnekow A, Jahn R, Schartl M. Synaptophysin: a substrate for the protein tyrosine kinase pp60c-src in intact synaptic vesicles. Oncogene. 1990;5(7):1019-1024.

61. Jena BP, Webster P, Geibel JP, Van den Pol AN, Sritharan KC. Localization of SH-PTP1 to synaptic vesicles: a possible role in neurotransmission. Cell Biol Int. 1997;21(8):469476.

This article is protected by copyright. All rights reserved. 
62. Yuan A, Sasaki T, Rao MV, et al. Neurofilaments form a Highly Stable Stationary Cytoskeleton After Reaching a Critical Level in Axons. J Neurosci. 2009;29(36):1131611329.

63. Uchida A, Tashiro T, Komiya Y, Yorifuji H, Kishimoto T, Hisanaga S-i. Morphological and biochemical changes of neurofilaments in aged rat sciatic nerve axons. $J$ Neurochem. 2004;88(3):735-745.

64. Hsieh ST, Crawford TO, Griffin JW. Neurofilament distribution and organization in the myelinated axons of the peripheral nervous system. Brain Res. 1994;642(1-2):316-326.

65. Hsieh ST, Kidd GJ, Crawford TO, et al. Regional modulation of neurofilament organization by myelination in normal axons. J Neurosci. 1994;14(11 Pt 1):6392-6401.

66. Pellegrino MA, Brocca L, Dioguardi FS, Bottinelli R, D'Antona G. Effects of voluntary wheel running and amino acid supplementation on skeletal muscle of mice. Eur J Appl Physiol. 2005;93(5-6):655-664.

67. Silveira WA, Goncalves DA, Graca FA, et al. Activating cAMP/PKA signaling in skeletal muscle suppresses the ubiquitin-proteasome-dependent proteolysis: implications for sympathetic regulation. $J$ Appl Physiol (1985). 2014;117(1):11-19.

68. Rudolf R, Bogomolovas J, Strack S, et al. Regulation of nicotinic acetylcholine receptor turnover by MuRF1 connects muscle activity to endo/lysosomal and atrophy pathways. Age (Dordr). 2013;35(5):1663-1674.

69. Zeman RJ, Zhao J, Zhang Y, et al. Differential skeletal muscle gene expression after upper or lower motor neuron transection. Pflügers Archiv - European Journal of Physiology. 2009;458(3):525-535.

This article is protected by copyright. All rights reserved. 
70. Moresi V, Williams AH, Meadows E, et al. Myogenin and Class II HDACs Control Neurogenic Muscle Atrophy by Inducing E3 Ubiquitin Ligases. Cell. 2010;143(1):35-45.

71. Xu Z, Feng X, Dong J, et al. Cardiac troponin $\mathrm{T}$ and fast skeletal muscle denervation in ageing. Cachexia, Sarcopenia Muscle. 2017(5):808-823.

72. Mei H, Ho MKC, Yung LY, Wu Z, Ip NY, Wong YH. Expression of Gaz in C2C12 cells restrains myogenic differentiation. Cell Signal. 2011;23(2):389-397.

73. Feng $\mathrm{Z}, \mathrm{Ko} \mathrm{CP}$. The role of glial cells in the formation and maintenance of the neuromuscular junction. Ann N Y Acad Sci. 2008;1132:19-28.

74. Thoenen H, Tranzer JP. Chemical sympathectomy by selective destruction of adrenergic nerve endings with 6-Hydroxydopamine. Naunyn Schmiedebergs Arch Exp Pathol Pharmakol. 1968;261(3):271-288.

75. Cojocel C, Thomson MS. Effect of 6-hydroxydopamine on gluconeogenesis in the rat renal cortex. Clin Exp Pharmacol Physiol. 2003;30(1-2):55-59.

76. Cojocel C, Thomson MS. Protective effect of resveratrol against 6-hydroxydopamineinduced impairment of renal p-aminohippurate transport. Arch Toxicol. 2004;78(9):525532.

77. Kim HP, Lee EJ, Kim SH, Han HM, Kim YC. Cell death and cytoskeletal alterations in cultured hepatic fat-storing cells induced by 6-hydroxydopamine. Res Commun Mol Pathol Pharmacol. 1998;101(1):59-68.

78. Navegantes LCC, Resano NMZ, Baviera AM, Migliorini RH, Kettelhut IC. Effect of sympathetic denervation on the rate of protein synthesis in rat skeletal muscle. Am J Physiol - Endocrinol Metab. 2004;286(4):E642-E647.

This article is protected by copyright. All rights reserved. 
79. Williams AH, Valdez G, Moresi V, et al. MicroRNA-206 delays ALS progression and promotes regeneration of neuromuscular synapses in mice. Science. 2009;326(5959):1549-1554.

80. Bongers KS, Fox DK, Ebert SM, et al. Skeletal muscle denervation causes skeletal muscle atrophy through a pathway that involves both Gadd45a and HDAC4. Am J Physiol- Endocrinol Metab. 2013;305(7):E907-E915.

81. Cohen TJ, Waddell DS, Barrientos T, et al. The histone deacetylase HDAC4 connects neural activity to muscle transcriptional reprogramming. J Biol Chem. 2007;282(46):33752-33759.

82. Furlow JD, Watson ML, Waddell DS, et al. Altered gene expression patterns in muscle ring finger 1 null mice during denervation- and dexamethasone-induced muscle atrophy. Physiol Genomics. 2013;45(23):1168-1185.

83. Straka T, Vita V, Prokshi K, et al. Postnatal Development and Distribution of Sympathetic Innervation in Mouse Skeletal Muscle. Int J Mol Sci. 2018;19(7).

84. Li G, Li Q-s, Li W-b, et al. miRNA targeted signaling pathway in the early stage of denervated fast and slow muscle atrophy. Neural Regen Res. 2016;11(8):1293-1303.

85. Jeng SF, Rau CS, Liliang PC, et al. Profiling muscle-specific microRNA expression after peripheral denervation and reinnervation in a rat model. $J$ Neurotrauma. 2009;26(12):2345-2353.

86. Horak M, Novak J, Bienertova-Vasku J. Muscle-specific microRNAs in skeletal muscle development. Dev Biol. 2016;410(1):1-13.

This article is protected by copyright. All rights reserved. 
87. Searl TJ, Silinsky EM. The phosphatidylinositol 4-kinase inhibitor phenylarsine oxide blocks evoked neurotransmitter release by reducing calcium entry through $\mathrm{N}$-type calcium channels. Br J Pharmacol. 2000;130(2):418-424.

88. Chandhok G, Soh MS. Presynaptic Deficits at Neuromuscular Junctions: A Specific Cause and Potential Target of Axonal Neuropathy in Type 2 Charcot-Marie-Tooth Disease. J Neurosci. 2016;36(31):8067-8069.

89. Jessen KR, Mirsky R. The repair Schwann cell and its function in regenerating nerves. $J$ Physiol. 2016;594(13):3521-3531.

90. de Waegh SM, Lee VM, Brady ST. Local modulation of neurofilament phosphorylation, axonal caliber, and slow axonal transport by myelinating Schwann cells. Cell. 1992;68(3):451-463.

91. Sakaguchi T, Okada M, Kitamura T, Kawasaki K. Reduced diameter and conduction velocity of myelinated fibers in the sciatic nerve of a neurofilament-deficient mutant quail. Neurosci Lett. 1993;153(1):65-68.

92. Ohara O, Gahara Y, Miyake T, Teraoka H, Kitamura T. Neurofilament deficiency in quail caused by nonsense mutation in neurofilament-L gene. $J$ Cell Biol. 1993;121(2):387-395.

93. Purves D, Augustine GJ, Fitzpatrick D, Hall WC, LaMantia AS, LE W. Neuroscience. 5th ed. Massachusetts, USA: Sinauer Associates, Inc.; 2011.

94. Bass M, Pant HC, Gainer H, Soderling TR. Calcium/calmodulin-dependent protein kinase II in squid synaptosomes. $J$ Neurochem. 1987;49(4):1116-1123.

95. Lee S, Pant HC, Shea TB. Divergent and convergent roles for kinases and phosphatases in neurofilament dynamics. J Cell Sci. 2014;127(18):4064-4077.

This article is protected by copyright. All rights reserved. 
96. Pant HC. Dephosphorylation of neurofilament proteins enhances their susceptibility to degradation by calpain. Biochem J. 1988;256(2):665-668.

97. Legate KR, Wickstrom SA, Fassler R. Genetic and cell biological analysis of integrin outside-in signaling. Genes Dev. 2009;23(4):397-418.

98. Vespa A, D'Souza SJ, Dagnino L. A novel role for integrin-linked kinase in epithelial sheet morphogenesis. Mol Biol Cell. 2005;16(9):4084-4095.

99. Vespa A, Darmon AJ, Turner CE, D'Souza SJ, Dagnino L. Ca2+-dependent localization of integrin-linked kinase to cell junctions in differentiating keratinocytes. $J$ Biol Chem. 2003;278(13):11528-11535.

100. Li B-S, Zhang L, Gu J, Amin ND, Pant HC. Integrin $\alpha 1 \beta 1$-Mediated Activation of Cyclin-Dependent Kinase 5 Activity Is Involved in Neurite Outgrowth and Human Neurofilament Protein H Lys-Ser-Pro Tail Domain Phosphorylation. J Neurosci. 2000;20(16):6055-6062.

101. Li BS, Daniels MP, Pant HC. Integrins stimulate phosphorylation of neurofilament NF-M subunit KSP repeats through activation of extracellular regulated-kinases (Erk1/Erk2) in cultured motoneurons and transfected NIH 3T3 cells. J Neurochem. 2001;76(3):703-710.

102. Moriscot AS, Baptista IL, Bogomolovas J, et al. MuRF1 is a muscle fiber-type II associated factor and together with MuRF2 regulates type-II fiber trophicity and maintenance. J Struct Biol. 2010;170(2):344-353.

103. Bodine SC, Latres E, Baumhueter S, et al. Identification of ubiquitin ligases required for skeletal muscle atrophy. Science. 2001;294(5547):1704-1708.

This article is protected by copyright. All rights reserved. 
104. Goncalves DA, Silveira WA, Lira EC, et al. Clenbuterol suppresses proteasomal and lysosomal proteolysis and atrophy-related genes in denervated rat soleus muscles independently of Akt. Am J Physiol Endocrinol Metab. 2012;302(1):E123-133.

105. Hirner S, Krohne C, Schuster A, et al. MuRF1-dependent regulation of systemic carbohydrate metabolism as revealed from transgenic mouse studies. J Mol Biol. 2008;379(4):666-677.

106. Bonaldo P, Sandri M. Cellular and molecular mechanisms of muscle atrophy. Dis Mod Mech. 2013;6(1):25-39.

107. Cuervo AM, Palmer A, Rivett AJ, Knecht E. Degradation of proteasomes by lysosomes in rat liver. Eur J Biochem. 1995;227(3):792-800.

108. Minetti GC, Feige JN, Rosenstiel A, et al. G $\alpha<\mathrm{sub}>\mathrm{i} 2</$ sub $>$ Signaling Promotes Skeletal Muscle Hypertrophy, Myoblast Differentiation, and Muscle Regeneration. Science Signaling. 2011;4(201):ra80.

109. Moxham CM, Malbon CC. Insulin action impaired by deficiency of the G-protein subunit Gi[alpha]2. Nature. 1996;379(6568):840-844.

110. Bowman WC, Raper C. Effects of sympathomimetics amines on neuromuscular transmission. Br J Pharmacol Chem. 1966;27(2):313-331.

111. Clarke BA, Drujan D, Willis MS, et al. The E3 Ligase MuRF1 Degrades Myosin Heavy Chain Protein in Dexamethasone-Treated Skeletal Muscle. Cell Metabol. 2007;6(5):376385.

112. Baron R, Janig W. Sympathetic and afferent neurons projecting in the splenic nerve of the cat. Neurosci Lett. 1988;94(1-2):109-113.

This article is protected by copyright. All rights reserved. 
113. Baron R, Janig W, Kollmann W. Sympathetic and afferent somata projecting in hindlimb nerves and the anatomical organization of the lumbar sympathetic nervous system of the rat. J Comp Neurol. 1988;275(3):460-468.

114. Noguchi E, Ohsawa H, Kobayashi S, Shimura M, Uchida S, Sato Y. The effect of electro-acupuncture stimulation on the muscle blood flow of the hindlimb in anesthetized rats. J Auton Nerv Syst. 1999;75(2-3):78-86.

115. Brumovsky PR, Seroogy KB, Lundgren KH, Watanabe M, Hokfelt T, Gebhart GF. Some lumbar sympathetic neurons develop a glutamatergic phenotype after peripheral axotomy with a note on VGLUT(2)-positive perineuronal baskets. Exp Neurol. 2011;230(2):258272.

116. Finch L, Haeusler G, Kuhn H, Thoenen H. Rapid recovery of vascular adrenergic nerves in the rat after chemical sympathectomy with 6-hydroxydopamine. Br J Pharmacol. 1973;48(1):59-72.

117. Zhang T, Pereyra AS, Wang ZM, et al. Calpain inhibition rescues troponin T3 fragmentation, increases Cav1.1, and enhances skeletal muscle force in aging sedentary mice. Aging Cell. 2016.

118. Renier N, Wu Z, Simon David J, Yang J, Ariel P, Tessier-Lavigne M. iDISCO: A Simple, Rapid Method to Immunolabel Large Tissue Samples for Volume Imaging. Cell. 2014;159(4):896-910.

119. Martinez-Pena y Valenzuela I, Pires-Oliveira M, Akaaboune M. PKC and PKA regulate AChR dynamics at the neuromuscular junction of living mice. PLoS One. 2013;8(11):e81311.

This article is protected by copyright. All rights reserved. 
120. Livak KJ, Schmittgen TD. Analysis of relative gene expression data using real-time quantitative PCR and the 2(-Delta Delta C(T)) Method. Methods. 2001;25(4):402-408.

121. Schmittgen TD, Livak KJ. Analyzing real-time PCR data by the comparative CT method. Nat Protocols. 2008;3(6):1101-1108.

122. Wilson CL, Miller CJ. Simpleaffy: a BioConductor package for Affymetrix Quality Control and data analysis. Bioinformatics. 2005;21(18):3683-3685.

123. Irizarry RA, Bolstad BM, Collin F, Cope LM, Hobbs B, Speed TP. Summaries of Affymetrix GeneChip probe level data. Nucleic Acids Res. 2003;31(4):e15.

124. Saeed AI, Sharov V, White J, et al. TM4: a free, open-source system for microarray data management and analysis. Biotechniques. 2003;34(2):374-378.

125. Pereyra AS, Wang ZM, Messi ML, et al. BDA-410 Treatment Reduces Body Weight and Fat Content by Enhancing Lipolysis in Sedentary Senescent Mice. J Gerontol A Biol Sci Med Sci. 2016.

This article is protected by copyright. All rights reserved. 


\section{Table 1}

Miniature End Plate Potentials (MEPPs) and End-Plate Potentials (EPPs) recorded in the lumbricalis muscle from sham and sympathectomized mice

\begin{tabular}{|c|c|c|c|c|c|c|c|}
\hline \multirow[t]{2}{*}{ MEPP } & \multicolumn{3}{|c|}{$\begin{array}{l}\text { Control (Sham) } \\
\text { (63 fibers; 8mice) }\end{array}$} & \multicolumn{4}{|c|}{$\begin{array}{l}\text { Sympathectomy } \\
\text { (79 fibers; } 6 \text { mice) }\end{array}$} \\
\hline & Mean & SE & & Mean & SE & & $P$-value \\
\hline Amplitude (mV) & 1.353 & \pm & 0.02 & 1.288 & \pm & 0.01 & 0.0001 \\
\hline Frequency $(\mathrm{Hz})$ & 0.928 & \pm & 0.09 & 0.684 & \pm & 0.06 & 0.0013 \\
\hline Time to Peak (ms) & 0.865 & \pm & 0.11 & 0.690 & \pm & 0.08 & 0.0907 \\
\hline Half decay time (ms) & 2.254 & \pm & 0.07 & 2.140 & \pm & 0.05 & 0.0067 \\
\hline Duration (ms) & 6.539 & \pm & 0.41 & 5.552 & \pm & 0.20 & 0.0020 \\
\hline \multirow[t]{2}{*}{ EPP } & \multicolumn{3}{|c|}{$\begin{array}{l}\text { Control (Sham) } \\
\text { (63 fibers; 8mice) }\end{array}$} & \multicolumn{4}{|c|}{$\begin{array}{l}\text { Sympathectomy } \\
\text { (79 fibers; } 6 \text { mice) }\end{array}$} \\
\hline & Mean & \multicolumn{2}{|c|}{ SEM } & Mean & \multicolumn{2}{|c|}{ SEM } & $p$-value \\
\hline Amplitude (mV) & 22.933 & \pm & 1.67 & 16.788 & \pm & 0.68 & 0.0004 \\
\hline Latency (ms) & 1.759 & \pm & 0.08 & 1.898 & \pm & 0.06 & 0.2346 \\
\hline Time to peak (ms) & 1.922 & \pm & 0.10 & 2.120 & \pm & 0.08 & 0.2517 \\
\hline Half-decay time (ms) & 2.804 & \pm & 0.14 & 2.922 & \pm & 0.10 & 0.4376 \\
\hline Quantal contents & 15.884 & \pm & 1.12 & 12.935 & \pm & 0.50 & 0.0093 \\
\hline
\end{tabular}

The number of fibres and mice examined for each group are between parentheses.

This article is protected by copyright. All rights reserved. 


\section{Table 2}

EPP plasticity in response to increasing nerve stimulation frequency

\begin{tabular}{|c|c|c|c|c|c|c|}
\hline \multirow[b]{2}{*}{ EPP Facilitation } & \multicolumn{2}{|c|}{$\begin{array}{l}\text { Control (Sham) } \\
\text { (57 fibers; } 9 \text { mice) }\end{array}$} & \multicolumn{4}{|c|}{$\begin{array}{l}\text { Sympathectomy } \\
\text { (64 fibers; } 6 \text { mice) }\end{array}$} \\
\hline & Mean & SEM & Mean & & & $P$-value \\
\hline $10 \mathrm{~Hz}$ & 1.01 & \pm 0.005 & 1.02 & \pm & 0.004 & 0.266 \\
\hline $25 \mathrm{~Hz}$ & 1.03 & \pm 0.006 & 1.03 & \pm & 0.005 & 0.190 \\
\hline $30 \mathrm{~Hz}$ & 1.03 & \pm 0.011 & 1.03 & \pm & 0.005 & 0.400 \\
\hline $50 \mathrm{~Hz}$ & 1.03 & \pm 0.006 & 1.04 & \pm & 0.005 & 0.155 \\
\hline $100 \mathrm{~Hz}$ & 1.06 & \pm 0.015 & 1.06 & \pm & 0.011 & 0.483 \\
\hline $150 \mathrm{~Hz}$ & 1.05 & \pm 0.013 & 1.07 & \pm & 0.019 & 0.204 \\
\hline EPP Depression & Mean & SEM & Mean & & & p-value \\
\hline $10 \mathrm{~Hz}$ & 0.83 & \pm 0.025 & 0.81 & \pm & 0.013 & 0.204 \\
\hline $25 \mathrm{~Hz}$ & 0.77 & \pm 0.034 & 0.78 & \pm & 0.009 & 0.392 \\
\hline $30 \mathrm{~Hz}$ & 0.79 & \pm 0.034 & 0.76 & \pm & 0.017 & 0.188 \\
\hline $50 \mathrm{~Hz}$ & 0.76 & \pm 0.018 & 0.75 & \pm & 0.014 & 0.297 \\
\hline $100 \mathrm{~Hz}$ & 0.70 & \pm 0.053 & 0.74 & \pm & 0.028 & 0.245 \\
\hline $150 \mathrm{~Hz}$ & 0.64 & \pm 0.064 & 0.75 & \pm & 0.051 & 0.087 \\
\hline
\end{tabular}

The number of fibres and mice examined for each group are between parentheses.

This article is protected by copyright. All rights reserved. 


\section{Figure Legends}

Figure 1. Lumbar sympathetic ganglia establish a functional connection with hindlimb

muscles. A. Paravertebral mouse sympathetic ganglia. All abdominal organs and the diaphragm have been excised to expose the paravertebral sympathetic ganglia from lumbar levels L2-L4. The bottom arrow shows the caudal joining of the ganglion chains. B-D. Immunostaining with TH antibody and staining for Hoechst 33342 (nuclei) of the paravertebral sympathetic ganglia segments. Calibration bar $=500 \mu \mathrm{m}$ and $50 \mu \mathrm{m}$ for $\mathbf{B}$ and $\mathbf{C}$, respectively. D. Lumbar sympathetic ganglia immunostained with TH antibody, stained with Hoechst 33342, and visualized with confocal microscopy. Z-stacks were generated by scanning 20 contiguous optical slices of $1.16 \mu \mathrm{m} / \mathrm{slice}$. Calibration bar $=100 \mu \mathrm{m}$. E-J. CTB-AF488 and -AF555 fluorescence in lumbar sympathetic ganglia $24 \mathrm{~h}$ after their injection into the TA and GA muscles. Images are representative of 3 experiments. Neuronal cell bodies in the sympathetic ganglia innervating GA (E) and TA (F) are stained with Hoechst 33342 (G) and immunostained with TH (H). Overlay image of $\mathbf{E}-\mathbf{G}$ is shown in $\mathbf{I}$. Overlay image of $\mathbf{E}-\mathbf{H}$ is shown in $\mathbf{J}$ (bar $=100 \mu \mathrm{m})$.

\section{Figure 2. Extensive regulation of gene transcription by skeletal muscle sympathetic} innervation. A. Volcano plot representing the significance (-Log10 p value) and magnitude of transcript change (Log fold change) in the GA muscle from sympathetic denervated and sham mice. B. Heatmap of 182 differentially expressed genes in the GA muscle from sympathetic denervated and sham mice (4 GA muscles from 4 mice per group). C. Functional enrichment analysis of differentially expressed transcripts determined by KEGG, Wikipathways, and Reactome databases. The red dotted line represents cutoff significance level of $P<0.01$.

This article is protected by copyright. All rights reserved. 
Figure 3. Sympathetic innervation regulates lumbricalis muscle innervation, tetanic muscle force generation, and the functional integrity of neuromuscular transmission.

A. Plantar nerve-lumbricalis muscle preparation. Arrows show muscle tendons. The green fluorescence corresponds to transgenic Thy $1+$ in the peroneal nerve. B. Confocal z-stack image of TH+ axons and AF555-BGT staining in the lumbricalis muscle from a sham mouse treated with iDISCO. ${ }^{118}$ C. Lumbricalis muscle lacking TH immunoreactivity 7 days after sympathectomy. D. Indirectly/directly elicited maximal muscle force ratio for sympathectomized and sham mice ( $\mathrm{n}=6-7$ lumbricalis muscles, 4 mice per group) as a function of stimulation frequency. Asterisks (*) indicate statistically significant differences $(P<0.05)$. E and $\mathbf{F}$ illustrate tetanic force recorded in response to supramaximal stimulation at $150 \mathrm{~Hz}$ for $3 \mathrm{~s}$ in sympathectomized and sham mice. Dashed lines indicate the baseline. Twitches were recorded in the peroneal nerve-lumbricalis muscle preparations from sham $(\mathbf{G})$ and sympathectomized $(\mathbf{H})$ mice used for high-frequency stimulation. Decreased MEPP frequency and amplitude recorded in the plantar nerve-lumbricalis preparation from sympathectomized and sham mice (I). SNS ablation induces decreased EPP amplitude. EPPs recorded in the lumbricalis muscle from sympathectomized and sham mice. EPP responses followed electrical pulses evoked by nerve stimulation at frequencies from $2-150 \mathrm{~Hz}(\mathbf{J})$.

Figure 4. SNS ablation evokes broad neurofilament dephosphorylation and depletion of synaptic vesicles in sympathectomized but not sham mice. Representative z-stack confocal images of lumbricalis muscle NMJ innervation from sham (A, C, E, and G) and sympathectomized (B, D, F, and $\mathbf{H})$ thy-1 transgenic mice. Thy-1+ motor axonal terminals (green) and BGT-680 (blue, cy5.5) (A, B) co-registered with nonphosphorylated NF antibody 
(red, AF568-SMI $311 \mathrm{Ab})(\mathbf{C}, \mathbf{D})$ in sham (A, C) and sympathectomized (B, D) mice. Thy-1+ axons overlap with phosphorylated NF (AF568-SMI $312 \mathrm{Ab}$ ) axons in sham (E, G) but not sympathectomized $(\mathbf{F}, \mathbf{H})$ mice. $\mathrm{N}=14$ random images from 6 lumbricalis muscles, 5 mice per group. Representative 2D z-stack confocal images of motor axons immunostained with SV2 antibody (red, AF568) and postterminal stained with BGT-680 (blue, cy5.5) in lumbricalis muscles from sham $(\mathbf{I}, \mathbf{K})$ and surgically sympathectomized $(\mathbf{J}, \mathbf{L})$ thy-1 (green) transgenic mice. SV2 immunostaining outlines the vascular (yellow arrow) and axonal (white arrows) trajectory in sham (K) but not sympathectomized (I) mice. Notice that axons and their terminals are thy-1+ in $\mathbf{J}$ and SV2 outlines axonal terminals in sham (K) and sympathectomized (I) mice. $\mathrm{N}=8$ confocal fields analyzed in 4 sham and 4 sympathectomized mice. Bar $=50 \mu \mathrm{m}$. M-P are closeups of the insets in i-l, displaying the postterminals stained with BGT (blue) and immunostained for SV2 (red). Calibration bar $=10 \mu \mathrm{m}$. Q-T show representative z-stack confocal images of NMJ postterminals stained with BGT-568 (red) and axon terminals immunostained with synaptophysin antibody (green, AF488) in lumbricalis muscles from sham and surgically sympathectomized mice. Calibration bar $=10 \mu \mathrm{m}$.

Figure 5. Sympathectomy induces NF-H and NF-M dephosphorylation and increased levels of PP2A and PP1 phosphatases. Levels of NF-H (A), NF-M (B), NF-L (C), phosphorylated NF-H and NF-M (d), and PP2A (e) and PP1 phosphatases (f) in the lysates of both sciatic-tibio-peroneal nerves from 3 sham and 3 surgically sympathectomized mice. Blots and SDS PAGE were probed for GAPDH and Commassie blue $(\mathbf{G}, \mathbf{H})$, respectively. Quantification of the NF immunoblots normalized to GAPDH show a significant increase in NFH and NF-M but not NF-H-L (I) with sympathectomy. Phosphorylated/non-phosphorylated ratio

This article is protected by copyright. All rights reserved. 
show decreased phosphorylation of both NF-H and NF-M subunits with sympathectomy. Levels of PP2A (E) and PP1 (F) phosphatases are significantly increased with sympathectomy expressed as a sym/sham ratio (K) or individual group measurements normalized to GAPDH (I). $* P<0.05, \dagger P<0.01$ and $\ddagger P<0.001$

Figure 6. Increased variability in myelin thickness and decrease axonal diameter with SNS ablation and increased expression of nerve neurotrophin and trophic factor genes in the sciatic-tibio-peroneal nerve after sympathectomy. Representative toluidine-blue staining of myelin in the peroneal nerve from sham- (A) and sympathetic-denervated mice (B). Calibration bar $=25 \mu \mathrm{m}$. Quantification of myelin thickness ( $\mathrm{n}=251$ and 233 axons) $(\mathbf{C})$ and axon diameter ( $\mathrm{n}=301$ and 466 axons) (D) in 4 nerves from 4 sham and 4 symptectomized mice, one nerve per mouse was analyzed. Electron microscopy of synaptic vesicles (SV) in axon buttons from 3 sham (1053 SV in 5 terminals) (e), and 3 sympathectomized (1042 SV in 5 terminals) mice (F). Calibration bar $=500 \mathrm{~nm}$. Quantification of mean synaptic vesicle (SV) area (G). qPCR analysis of neurotrophins and trophic factor $\mathrm{p} 75^{\mathrm{NTR}}$ receptor, BDNF, and GDNF mRNAs and Schwann cell reprogramming transcripts, adaptor related protein complex 1 beta 1subunit (AP1B1), Myelin protein zero (MPZ), ERG2/Krox20, myelin basic protein (MBP), and neural-cell adhesion molecule, (NCAM). Values, expressed as fold change of sympathectomized compared to sham mice, are means of 3 nerves from either sham or sympathectomized mice, each studied in triplicate (H). $* P<0.05$ and $\ddagger P<0.001$

This article is protected by copyright. All rights reserved. 
Figure 7. Sympathetic innervation prevents skeletal muscle atrophy and SNS ablation leads to specific muscle fiber-subtype atrophy in GA and TA muscles. H\&E staining of TA and GA muscles from sham (top) and sympathectomized (bottom) mice (A) showed significant reduction in mean CSA (B) and a shift toward smaller fibers in the relative-frequency histograms (c) $(\mathrm{n}=4$ mice, 6 muscles per group) (C). Representative cross sections of TA and GA muscles from sham (top) and sympathectomized (bottom) mice (D). Myofiber were immunostained with specific MHC antibodies to identify type-I (blue secondary Ab), -IIa (green), and -IIb (red) fibers. Fibers negative to these three antibodies were labeled IIx. ${ }^{45}$ Panels $\mathbf{E}$ and $\mathbf{F}$ examine muscle fiber composition and muscle fiber CSA, respectively. The number of fibers studied was 6,249 in 4 GA muscles from 4 mice per group; 5,603 in 4 TA from 4 mice per group, and 2,525 in 4 soleus from 3 mice per group. Calibration bar $=100 \mu \mathrm{m} . * P<0.05, \uparrow P<0.01$ and $\ddagger P<$ 0.001

\section{Figure 8. The SNS regulates MuRF1 expression to partition AChR between sarcolemmal} and subsarcolemmal domains and SNS ablation increases the total pool of AChR in the GA muscle. A. Pull-down and immunoblot analysis of membrane AChR expression in the GA and/or TA muscles from sympathectomized, sympathectomized infected with AAV$\mathrm{G} \alpha_{\mathrm{i} 2}(\mathrm{Q} 205 \mathrm{~L})$, and sham wild-type and sham and sympathectomized MuRF1KO mice. B. Statistical analysis of 3-5 muscles from 3-4 mice per group. D. Pull-down and immunoblot analysis of total AChR expression in GA and/or TA muscles from sympathectomized, sympathectomized infected with $\mathrm{AAV}-\mathrm{G \alpha}_{\mathrm{i} 2}(\mathrm{Q} 205 \mathrm{~L})$, and sham wild-type and MuRF1KO mice. D. Statistical analysis of 3-5 muscles from 4 mice per group. GAPDH was used as the internal control for membrane and total AChR analysis. $* P<0.05, \dagger P<0.01$ and $\ddagger P<0.001$ 
Figure 9. The SNS regulates muscle MuRF1 expression. A. Increased MuRF1 with sympathetic denervation in TA and GA muscles. Differences between sympathectomized and sham mice ( $n=4$ mice per group) were statistically significant for both GA and TA muscles. The difference between groups disappears when the TA muscle from sympathectomized mice was

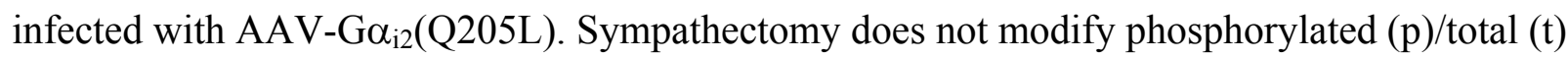

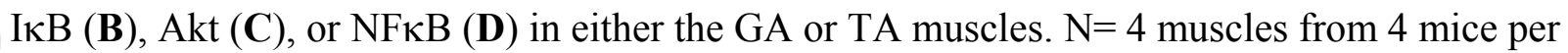
sham or sympathectomized mice. $* P<0.05$ and $\dagger P<0.01$

Figure 10. Sympathetic denervation upregulates muscle Hdac4, myogenin, and $\beta 2-A R$ expression, and downregulates $G \alpha i 2$, which is prevented by $G \alpha_{i 2}(Q 205 L)$ expression. Sympathectomy induces significant increases in Hdac4 in the GA muscle (A) and myogenin in both muscles (B), which significantly decreased with $\mathrm{G \alpha}_{\mathrm{i} 2}(\mathrm{Q} 205 \mathrm{~L})$ treatment. $\beta 2-\mathrm{AR}$ significantly increases with sympathectomy and decreases with sympathectomy plus $\mathrm{G}_{\alpha \mathrm{i} 2}$ overexpression only in the TA muscle $(\mathbf{C}) \cdot \mathrm{G}_{\alpha \mathrm{i} 2}$ decreased in the TA and GA muscles with sympathectomy, which was prevented by AAV-Ga $\alpha_{i 2}(\mathrm{Q} 205 \mathrm{~L})$ treatment in the TA muscle (D), N $=4$ GA or TA muscles from 4 mice per group. ${ }^{*} P<0.05$ and $\dagger P<0.01$

\section{Figure 11. Sympathetic denervation leads to increased expression of motor denervation} genes and miR-206. qPCR analysis of gene expression shows increased myogenin, Fbxo32, and Chrng at day 7 (A) while MuRF1, Fbxo32, Hdac4, and Chrng were increased at day 3 (B), after sympathectomy. FoxO1, FoxO3, and Gadd45a were not modified at either timepoint in GA or TA muscles. miR-206 expression increases in the TA muscle and serum levels 7 days after sympathectomy. $\mathrm{N}=4 \mathrm{TA}$ and GA muscles from 4 mice per group (C). The results are presented 
as fold-changes relative to muscles or serum from sham mice (set at 1-fold). qPCR analysis of changes in Myogenin, Fbxo32, and Chrng gene expression were significant at day 7 after sympathectomy (A). P values for differences in MuRF1, Hdac4, Fbxo32, Chrng, and Chrna1 expression were also significant for the GA and TA, except for Chrnal in the TA, muscle 3 days after sympathectomy (B). FoxO1, FoxO3, and Gadd45a were not significantly modified in GA or TA muscles at either timepoint. MiR-206 expression increased in the TA muscle and serum levels 7 days after sympathectomy. The $\mathrm{P}$ value for the GA muscle was not significant. * $P<$ $0.05, \dagger P<0.01$ and $\ddagger P<0.001$

Figure 12. Model for SNS regulation of NMJ. The SNS regulates NMJ motor axon vesicle release and postsynaptic AChR stability through the $\mathrm{G}_{\mathrm{\alpha i2} 2}$-Hdac4-myogenin-MuRF1-miR-206 pathway.

This article is protected by copyright. All rights reserved. 


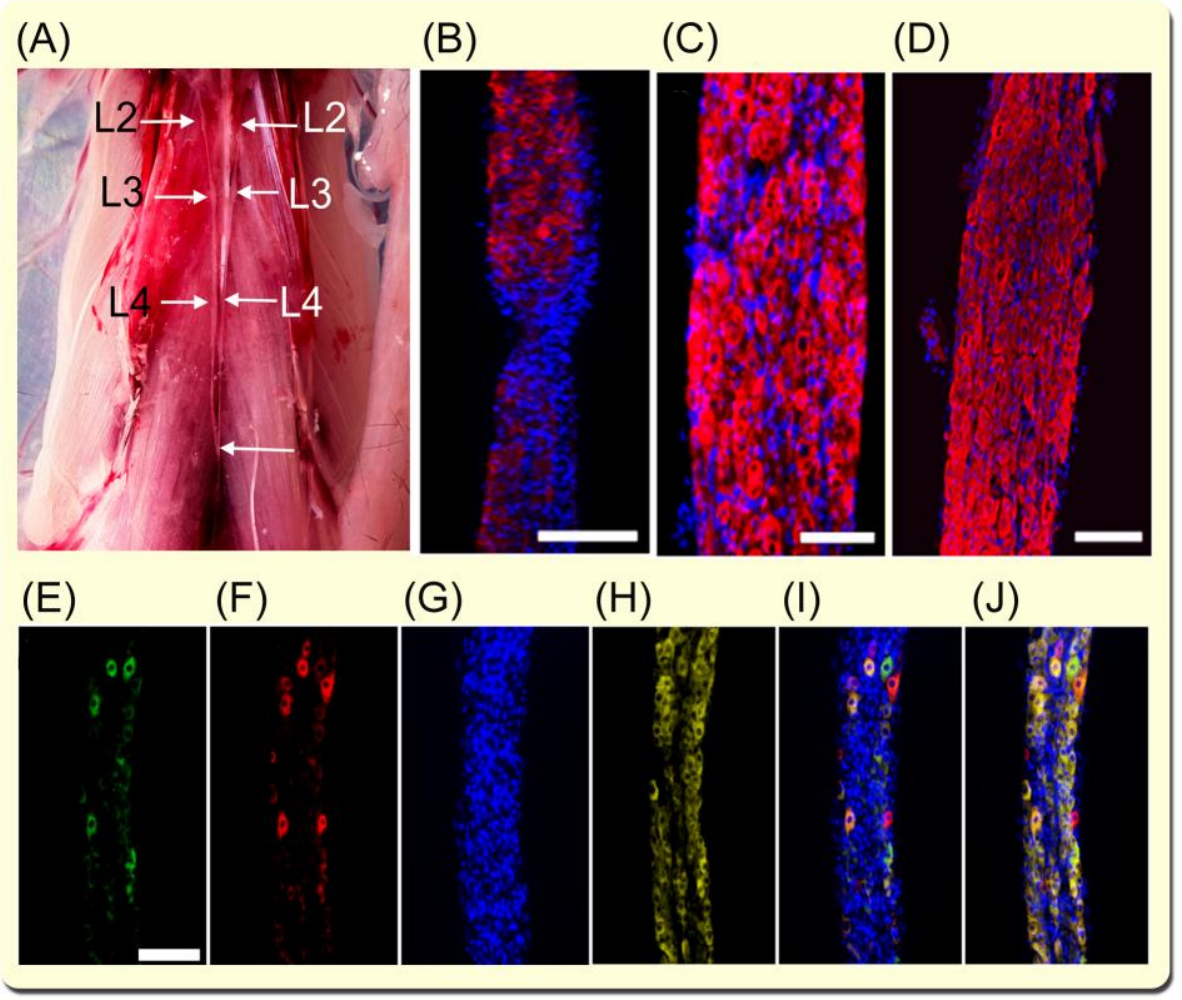

This article is protected by copyright. All rights reserved. 
(A)

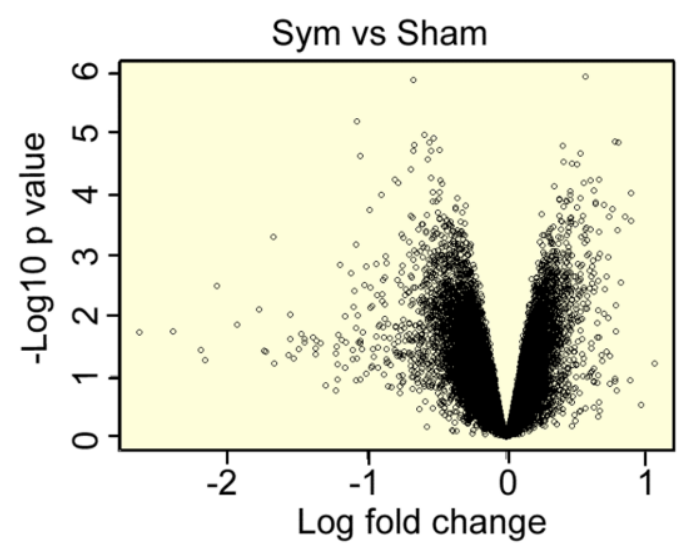

(C)

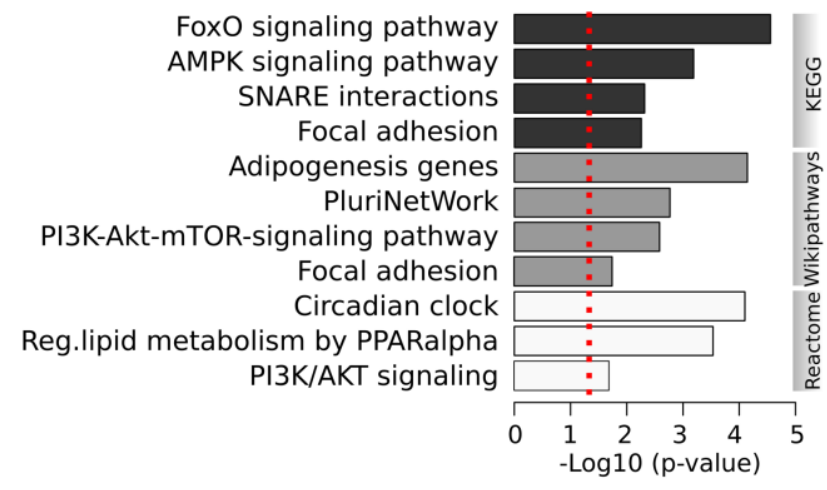

(B)
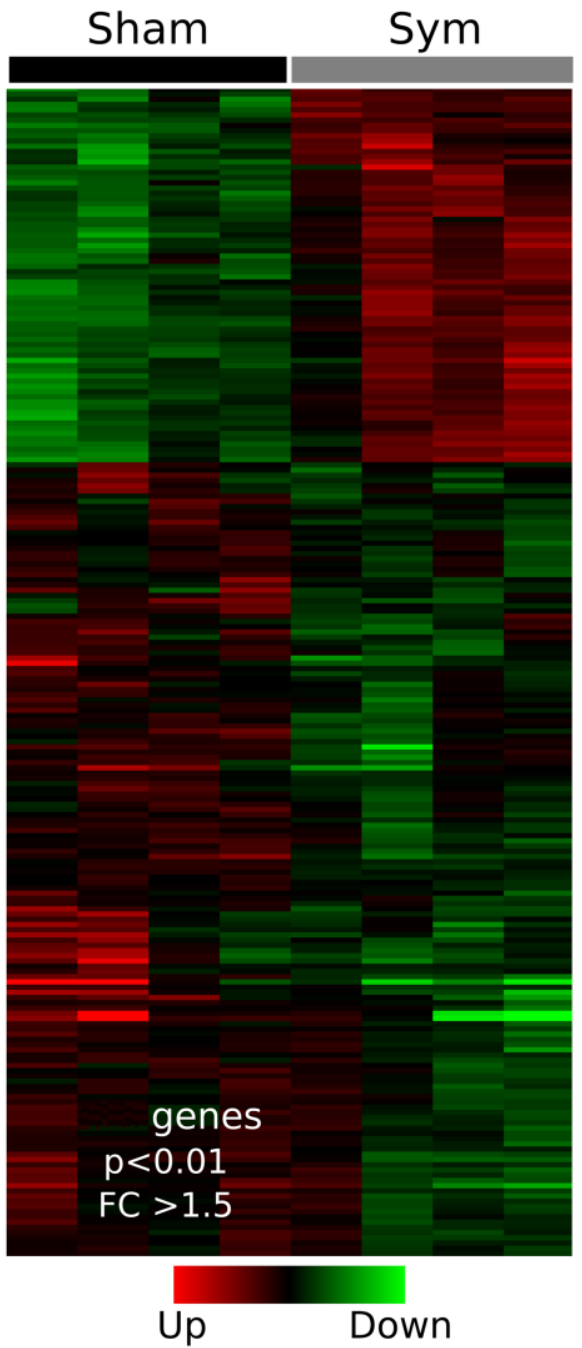

This article is protected by copyright. All rights reserved. 
(A)

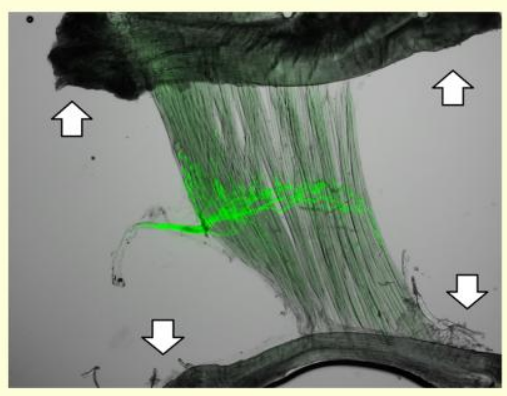

(D)

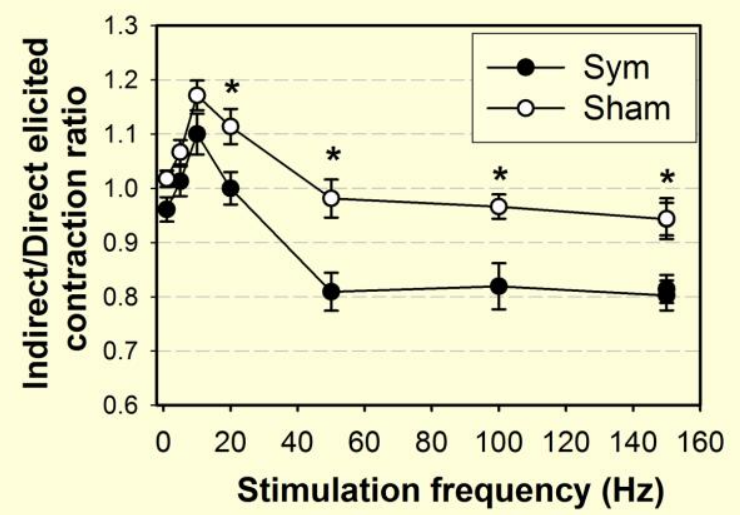

(E)

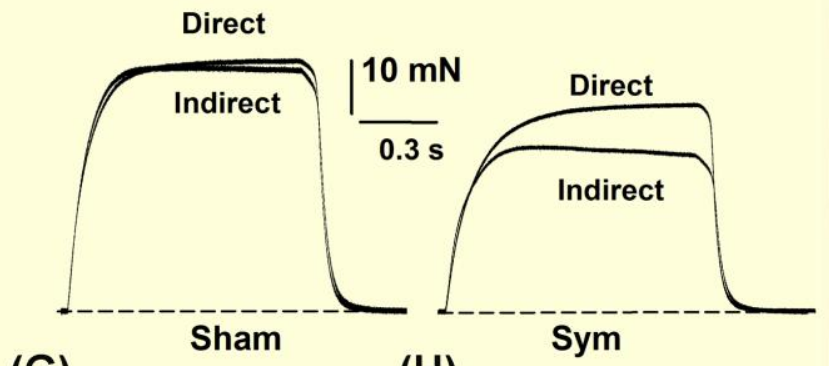

(G)

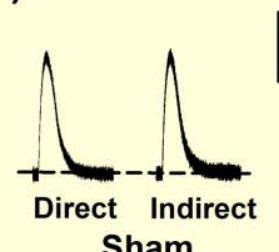

Sham
(B)

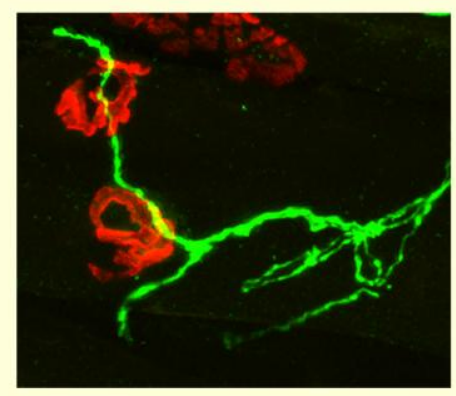

(I)
(C)
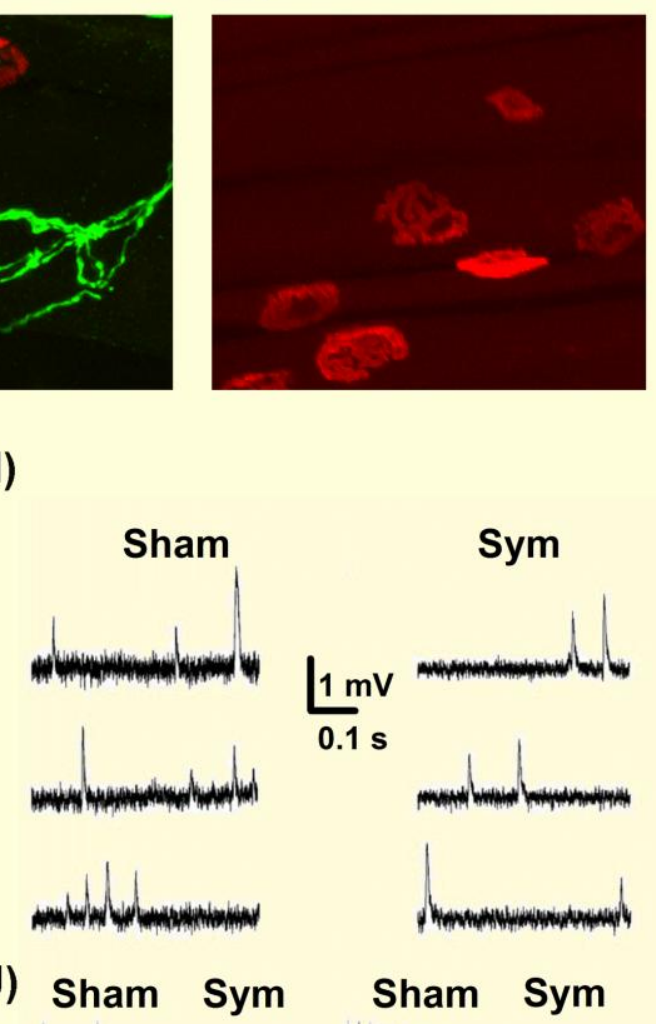

$2 \mathrm{~Hz}$

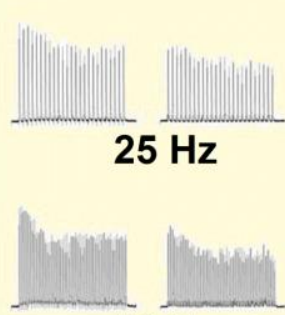

$50 \mathrm{~Hz}$
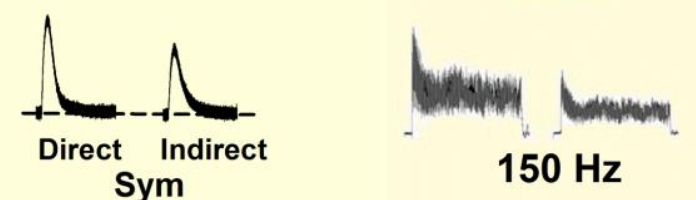

$150 \mathrm{~Hz}$

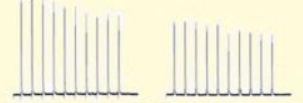

$10 \mathrm{~Hz}$
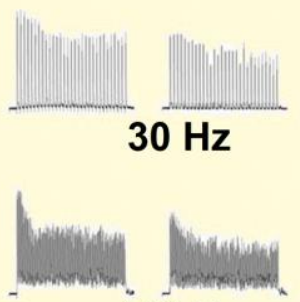

$100 \mathrm{~Hz}$

$20 \mathrm{mV}$

$600 \mathrm{~ms}$

This article is protected by copyright. All rights reserved. 
Sham

(A)Thy-1 BGT NF-SV2(B) Thy-1 BGT NF-SV2 (C) NF

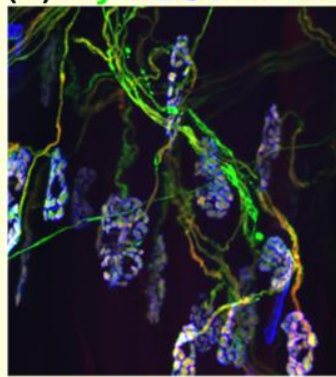

(E) Thy-1 BGT P-NF

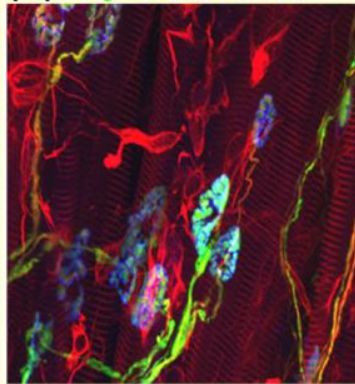

(I) Thy-1 BGT SV2

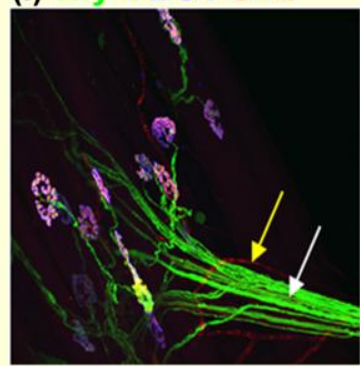

(M)BGT

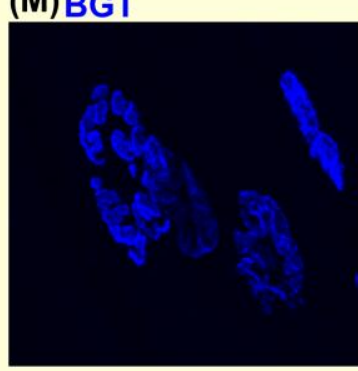

(Q) BGT

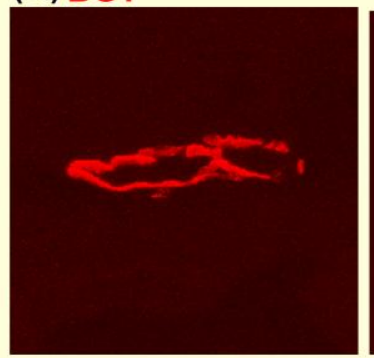

Sym

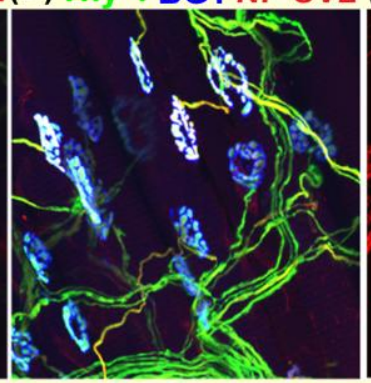

Sham

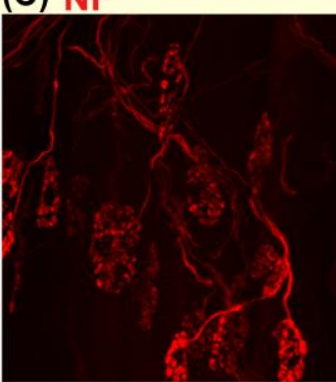

(F) Thy-1 BGT P-NF (G) P-NF

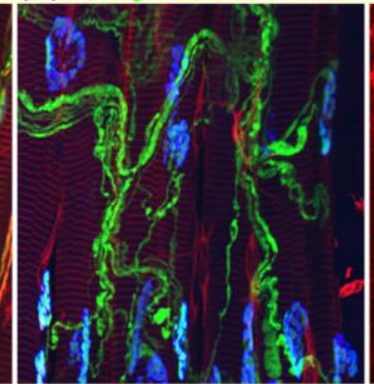

(J) Thy-1 BGT SV2

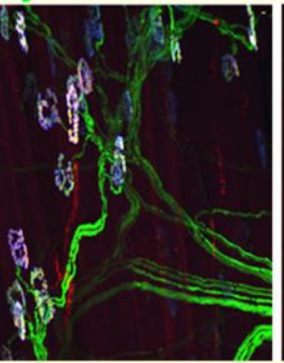

(N)BGT

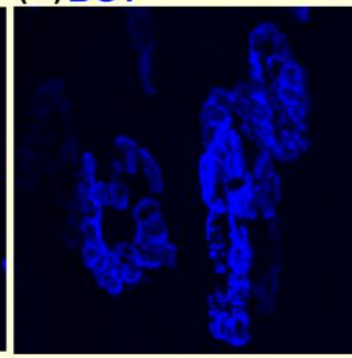

(R) BGT

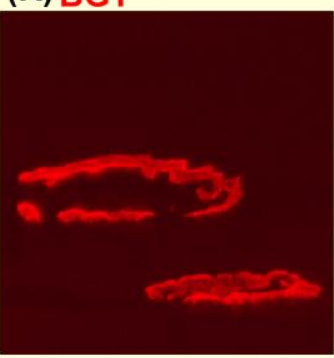

(K) SV2

(0) SV2

(S) Synaptophysin
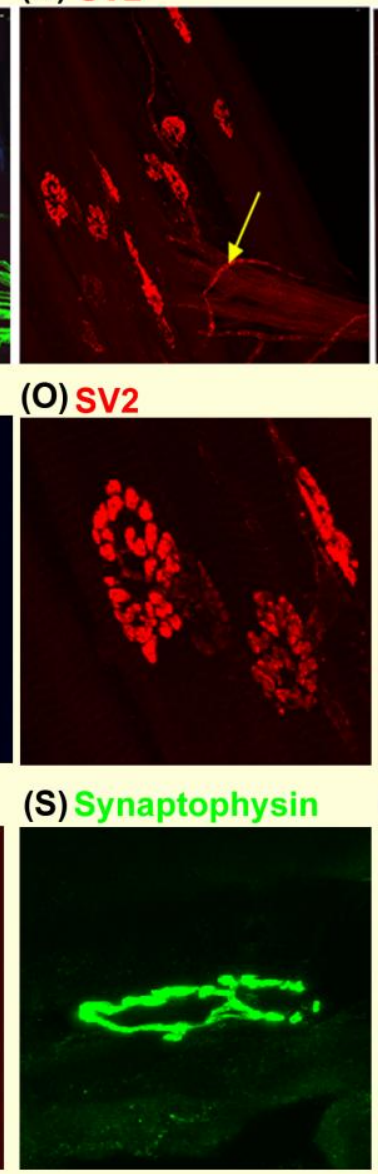

(D) NF
(S) Synaptophysin

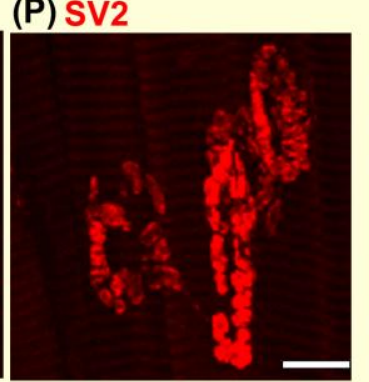

(L) SV2

(H) P-NF

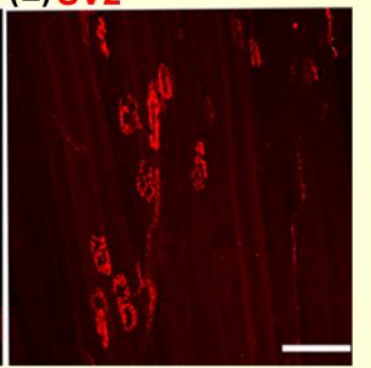

(P) SV2

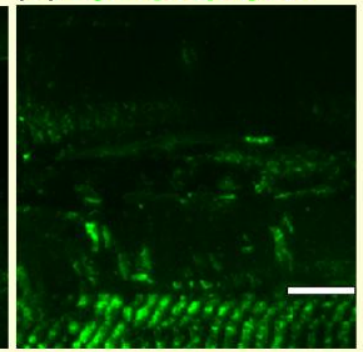

This article is protected by copyright. All rights reserved. 
(A)

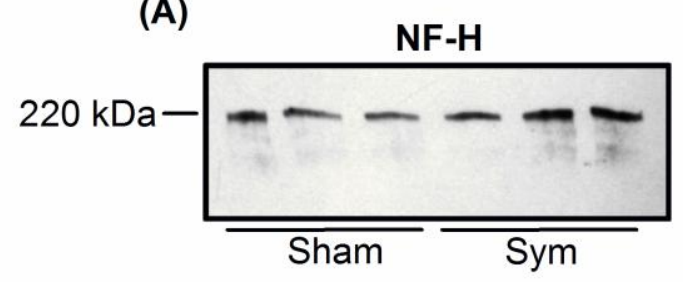

(B)
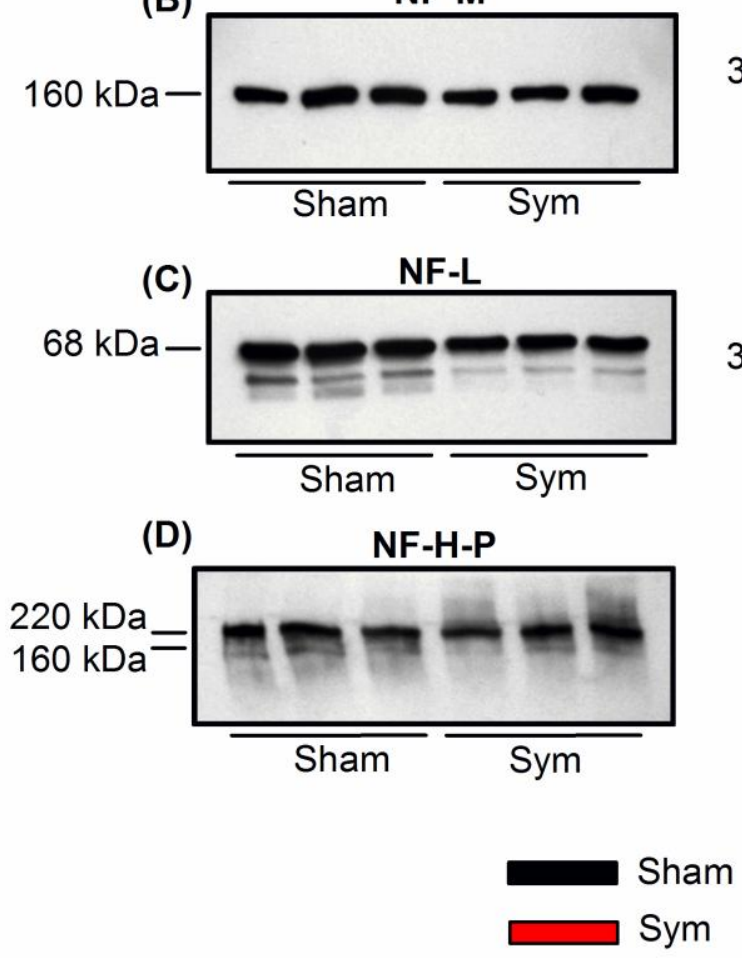

(l)

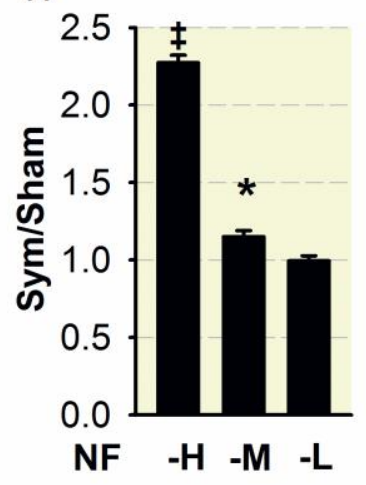

(J)

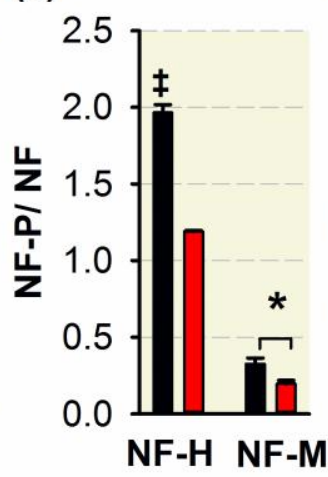

(K)
(E)

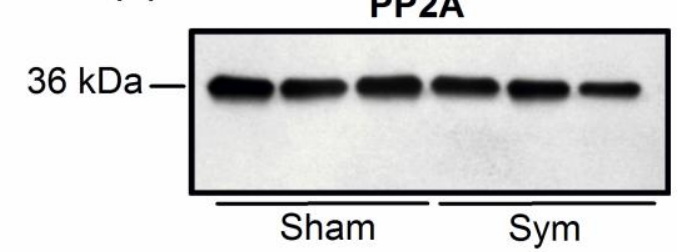

(F)

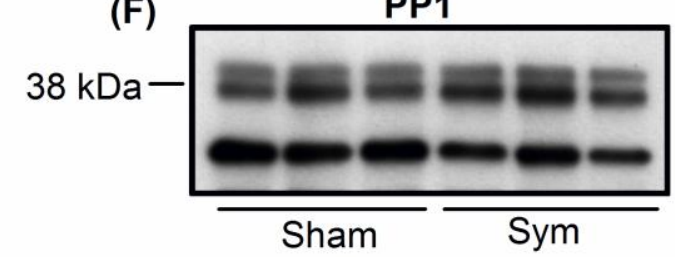

(G)

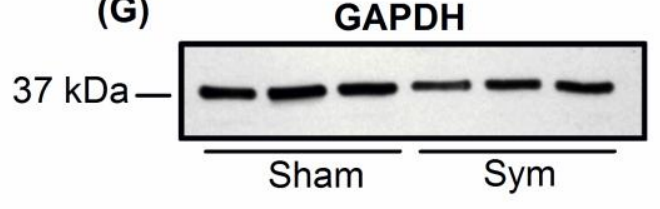

(H)

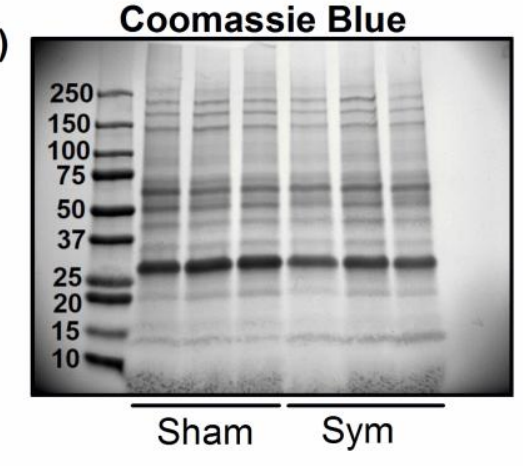

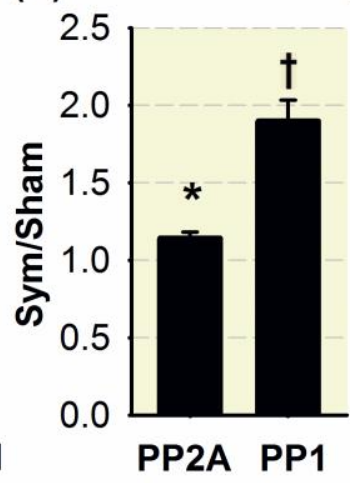

(L)

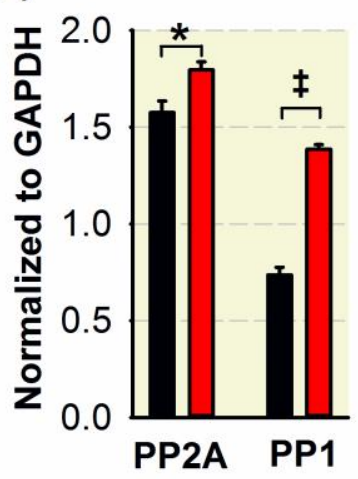

This article is protected by copyright. All rights reserved. 
(A)

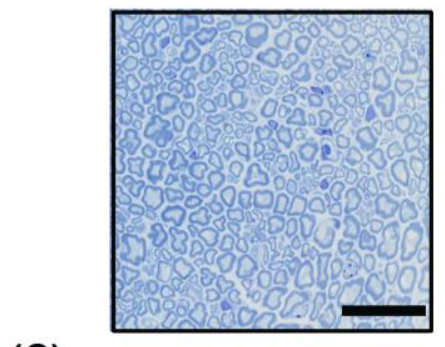

(C)

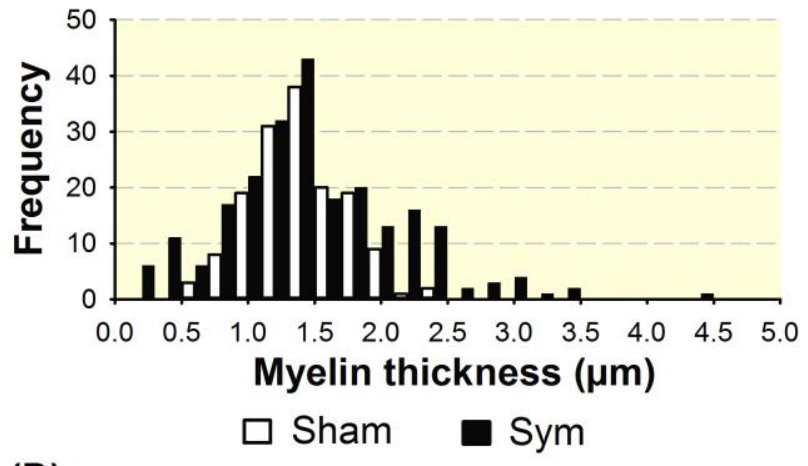

(D)

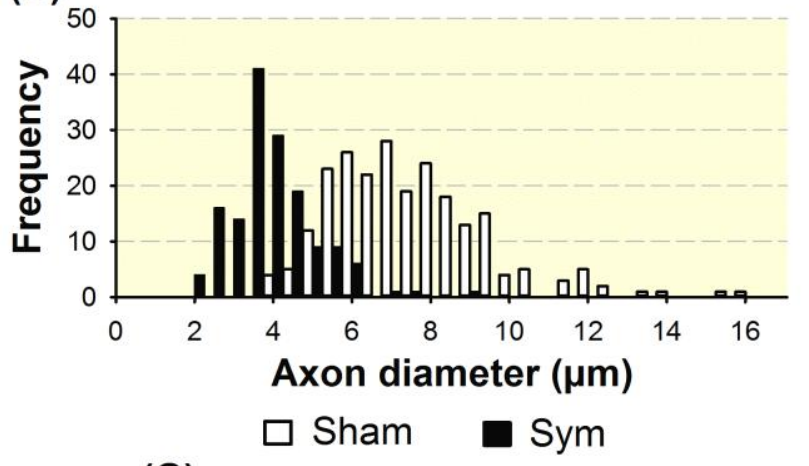

(G)

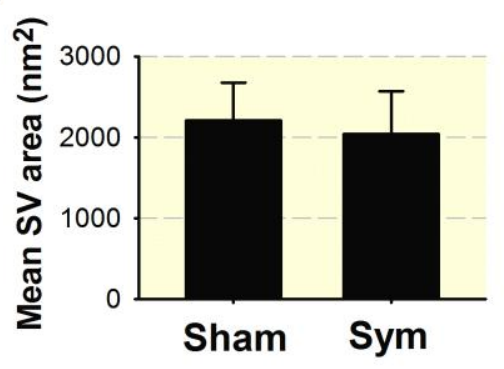

(E)

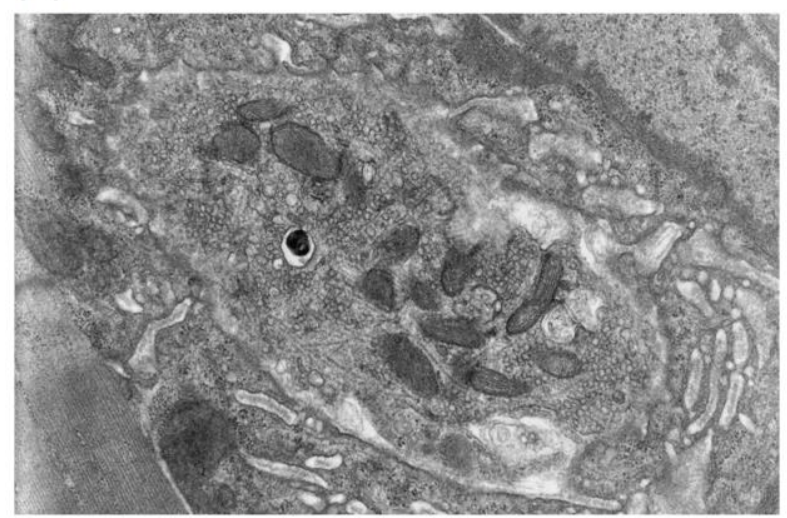

(F)

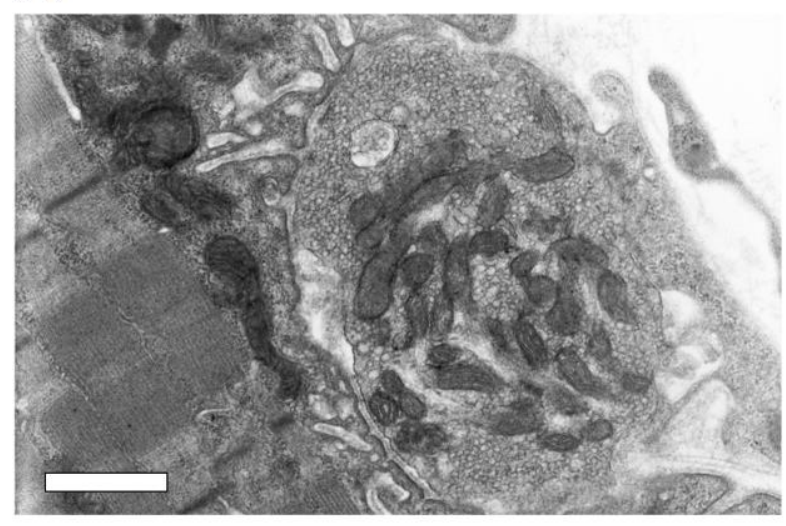

(H)

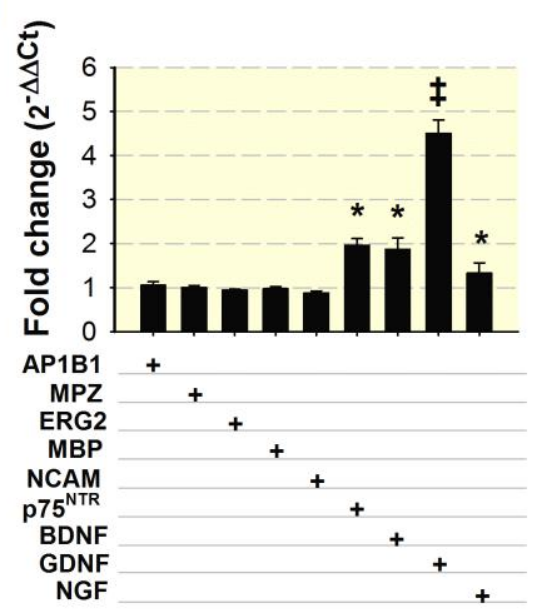

This article is protected by copyright. All rights reserved. 

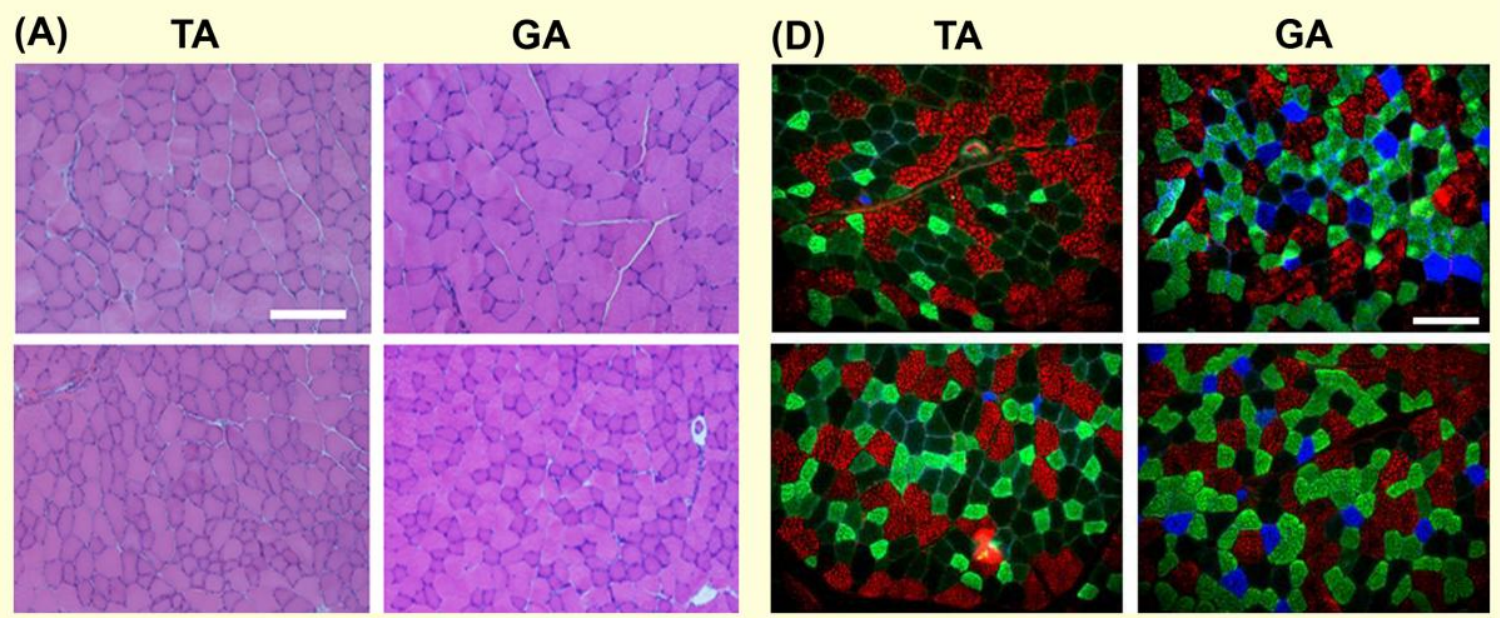

(B) $\approx 2.2$

- 2.2 ,
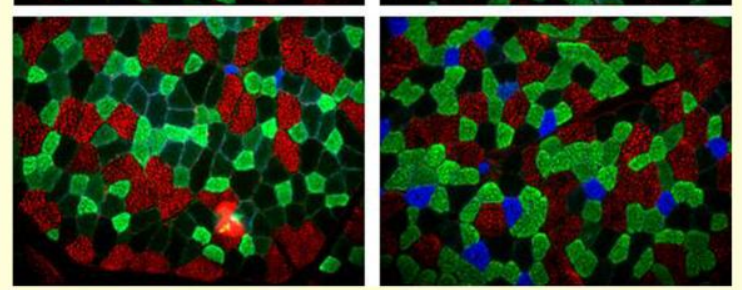

(E) ๘

This article is protected by copyright. All rights reserved. 
(A)

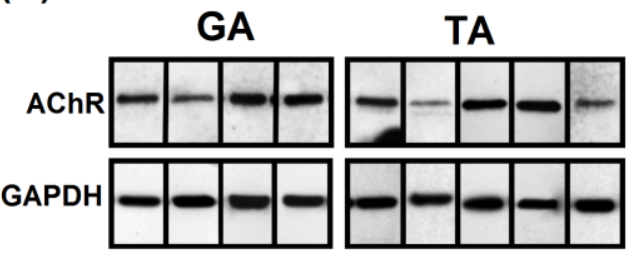

(B)
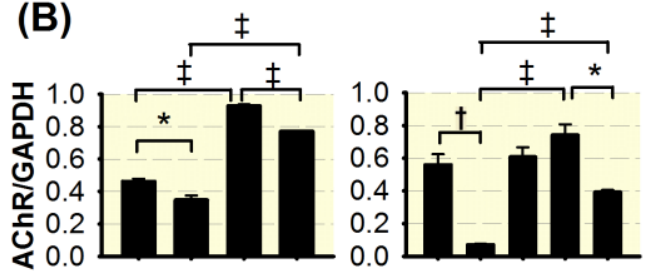

Membrane sham

Membrane sym

Membrane MuRF1KO sham

Membrane MuRF1KO sym

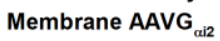

Total sham

Total sym

Total MuRF1KO sham

Total MuRF1KO sym

(C)

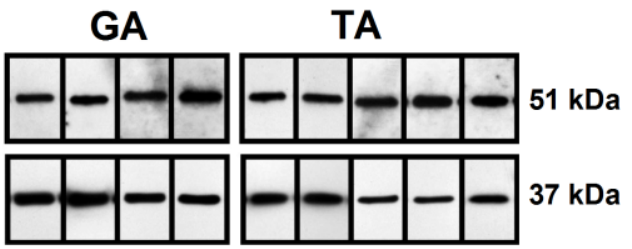

(D)

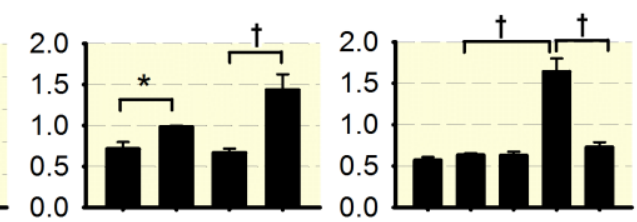

Total AAVG

This article is protected by copyright. All rights reserved. 


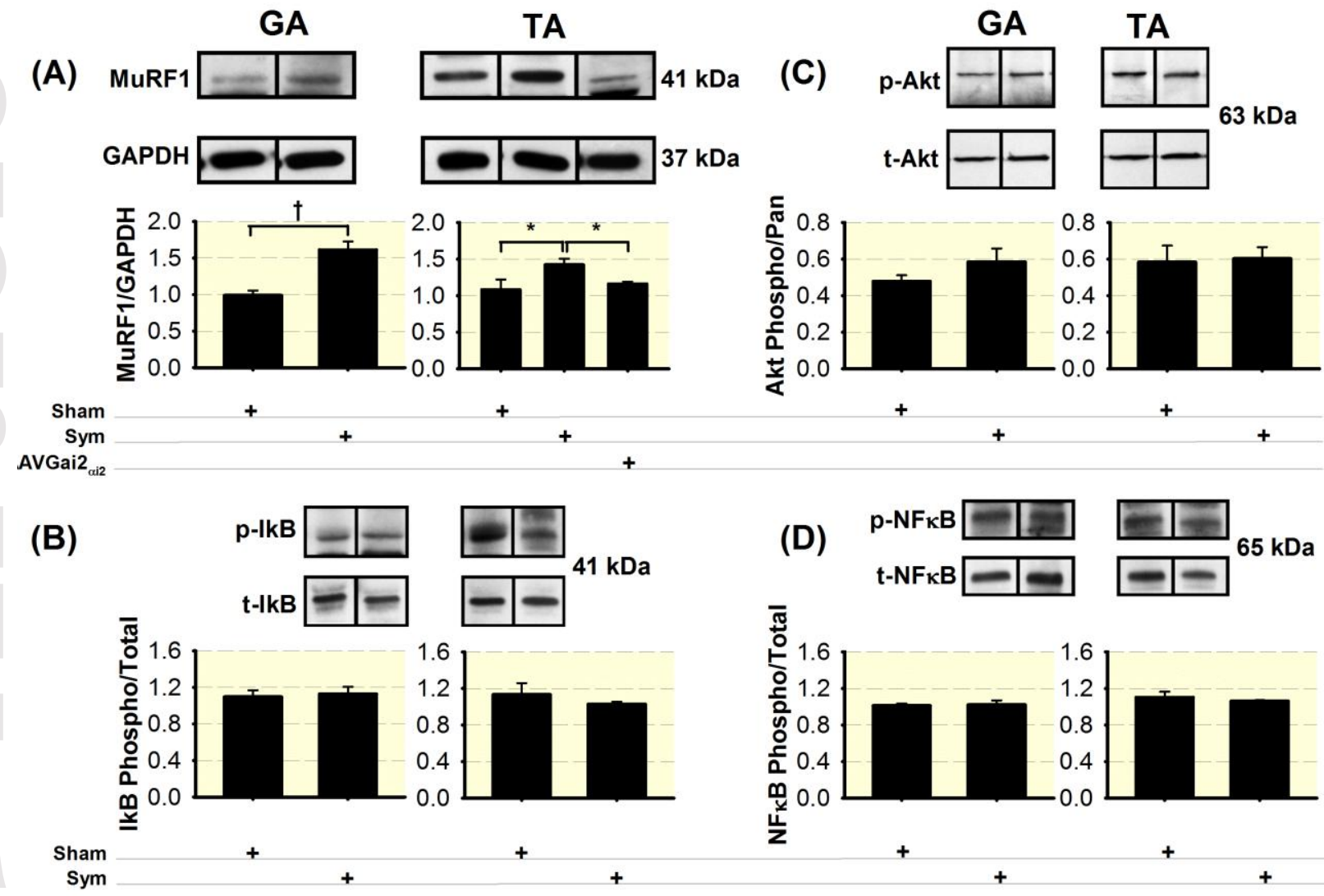

This article is protected by copyright. All rights reserved. 
(A)
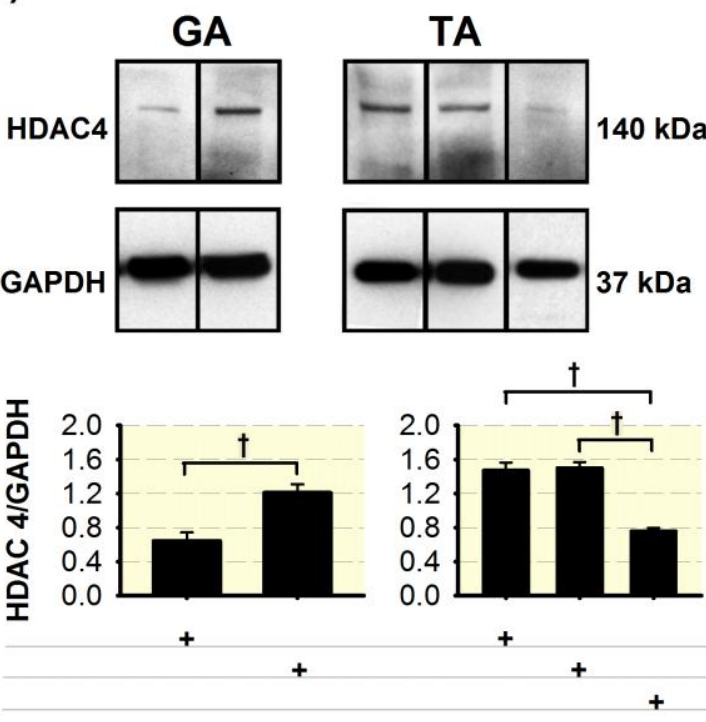

(C)
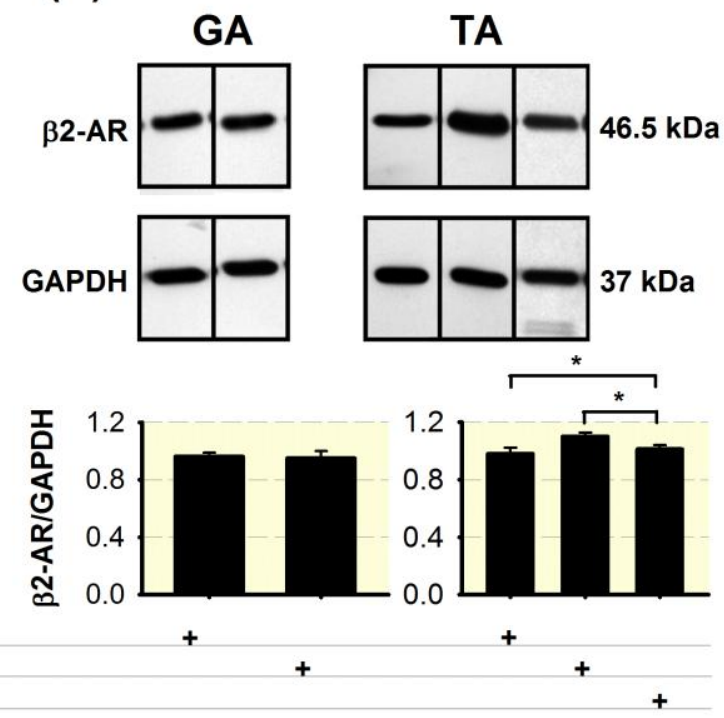

(B)
(D)

24 kDa

Gai2

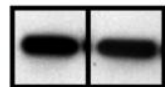

$37 \mathrm{kDa}$
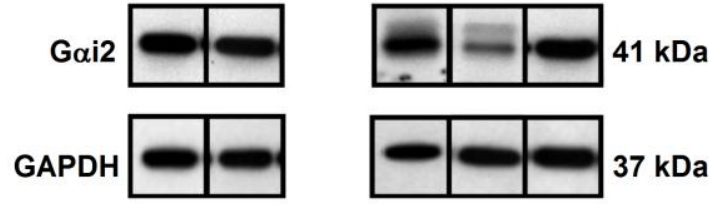

GAPDH

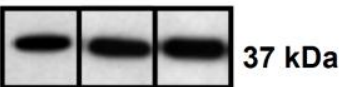

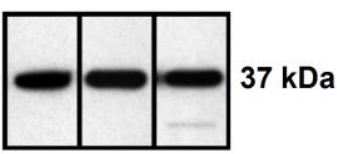

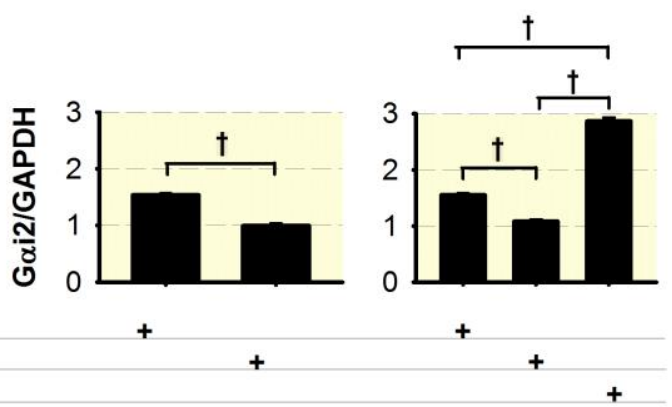

This article is protected by copyright. All rights reserved. 


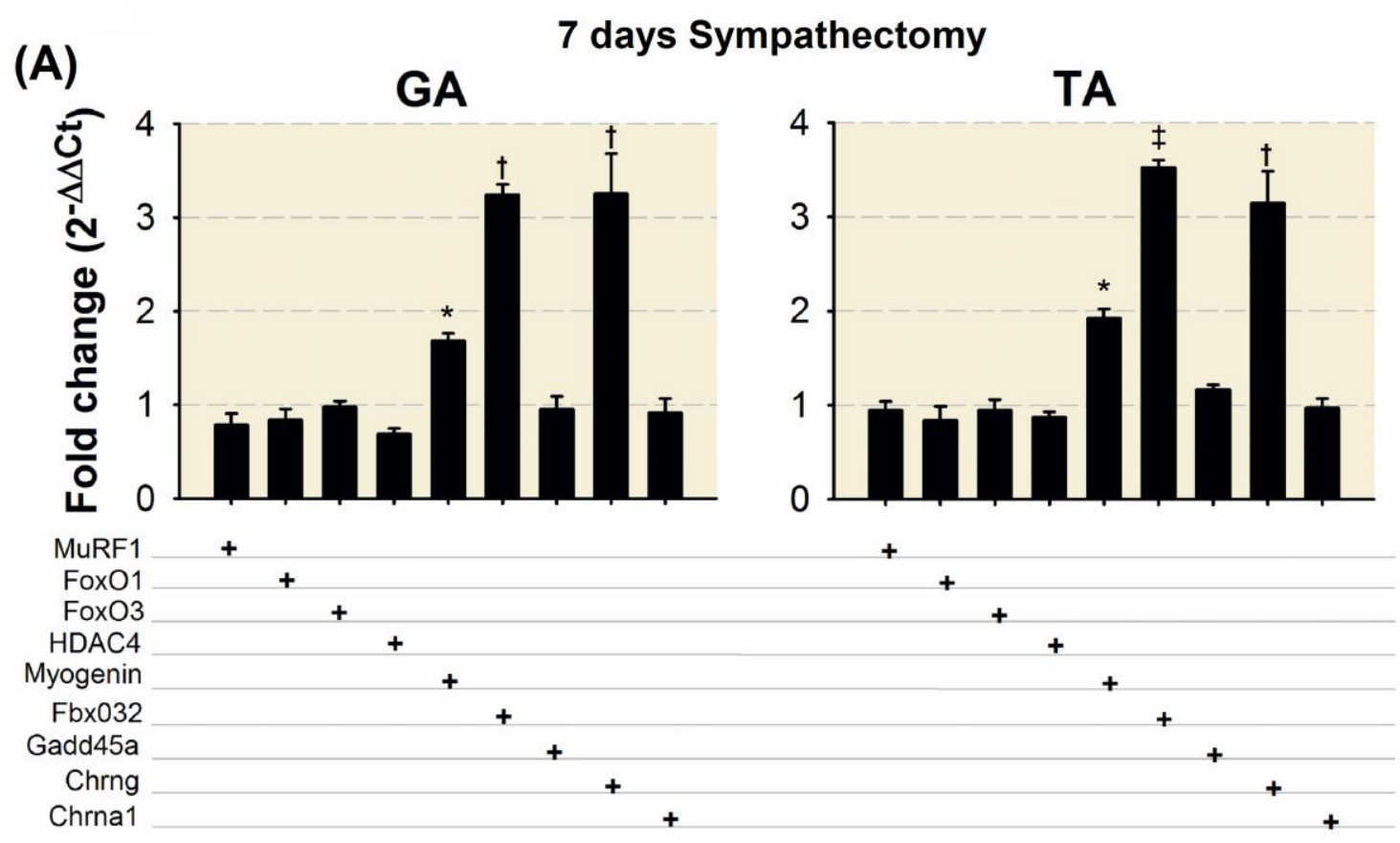

(B)

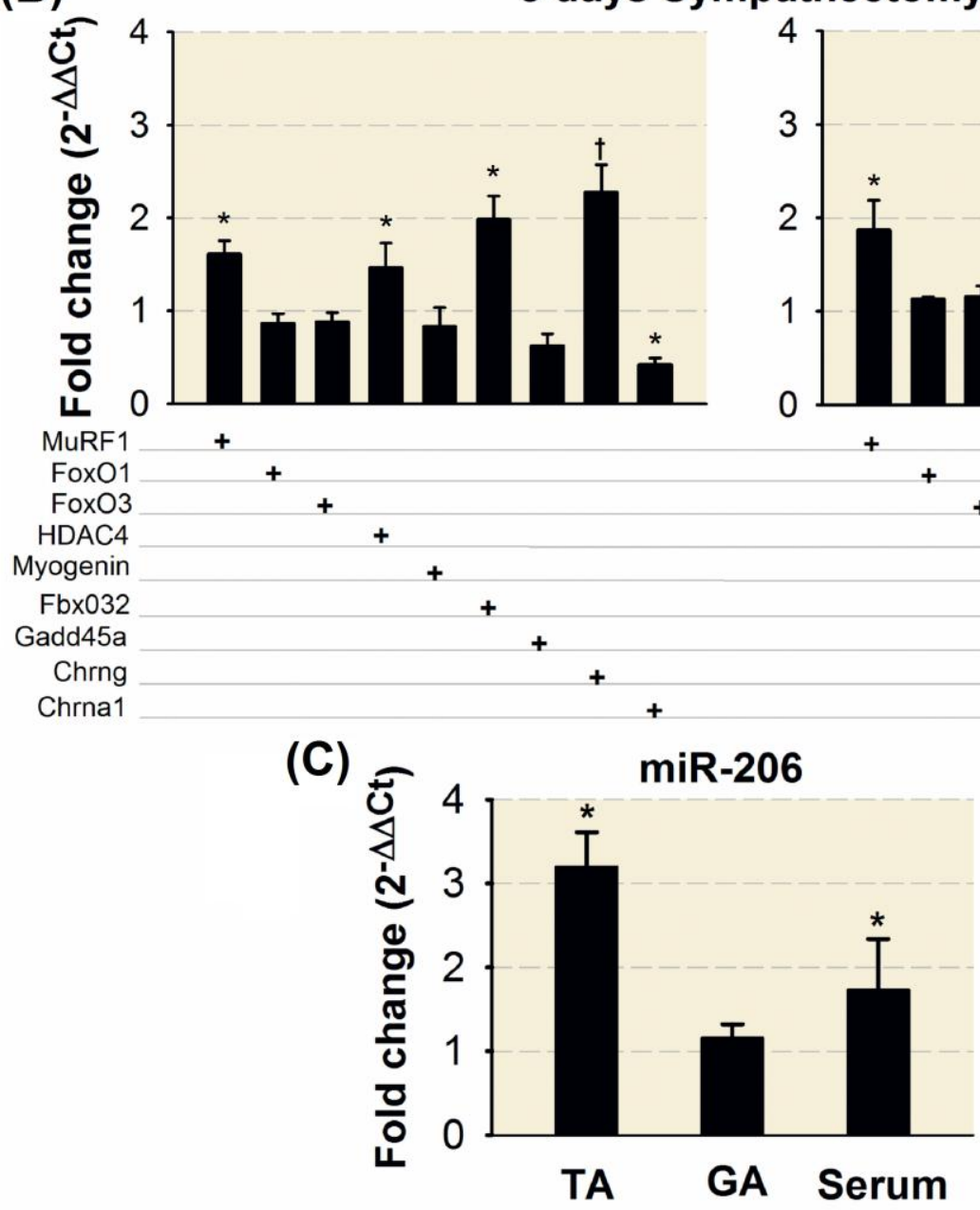

This article is protected by copyright. All rights reserved. 


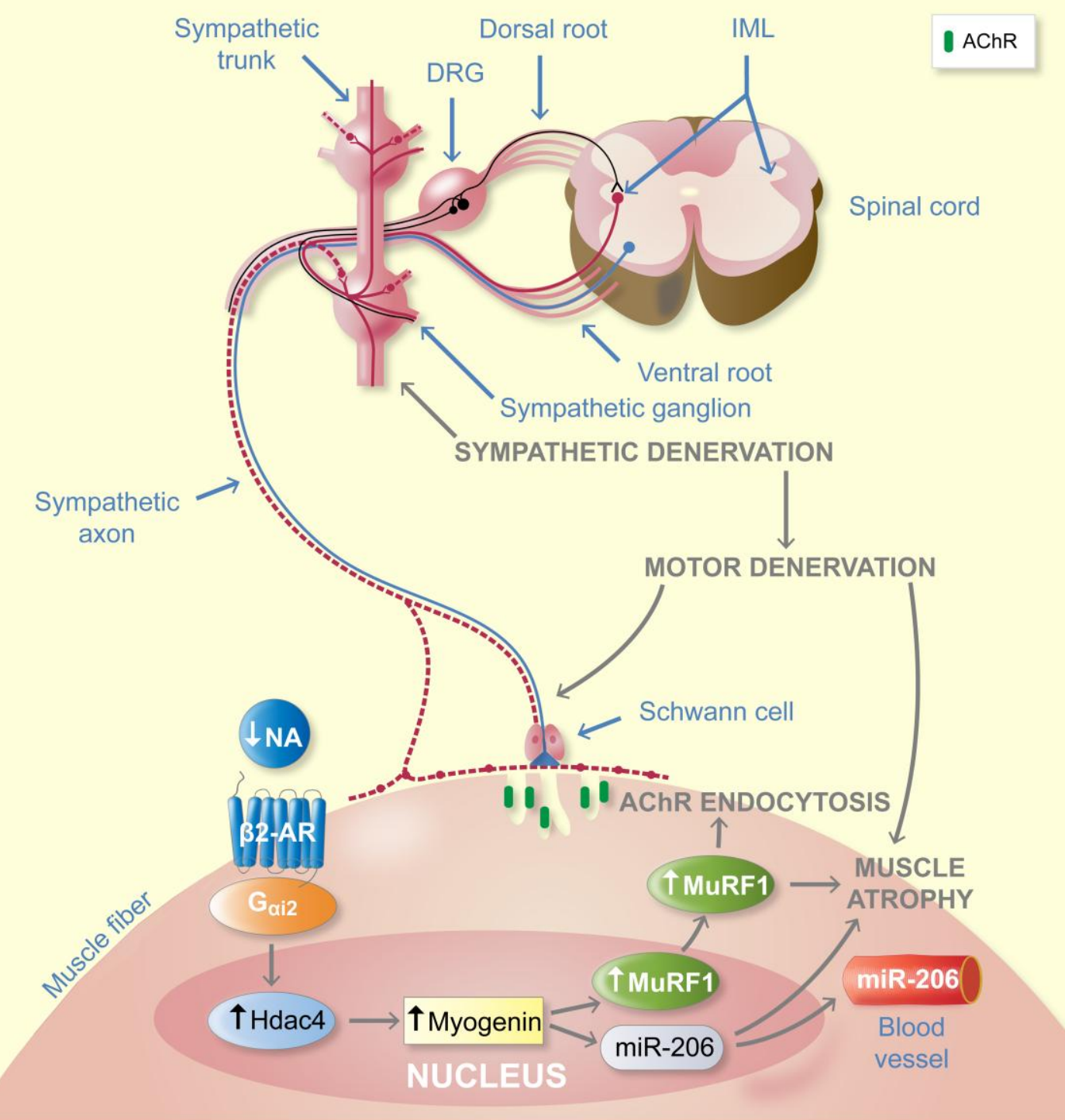

This article is protected by copyright. All rights reserved. 